UNIVERSIDADE DE SÃO PAULO

ESCOLA DE ENFERMAGEM DE RIBEIRÃO PRETO

VANESSA DE BRITO POVEDA

\title{
Análise dos fatores predisponentes à infecção do sítio cirúrgico em gastrectomia
}


VANESSA DE BRITO POVEDA

\section{Análise dos fatores predisponentes à infecção do sítio cirúrgico em gastrectomia}

Dissertação de Mestrado apresentada à Escola de Enfermagem de Ribeirão Preto da Universidade de São Paulo, para concorrer ao título de Mestre pelo Programa de Pós-Graduação em Enfermagem Fundamental do Departamento de Enfermagem Geral e Especializada, inserida na linha de pesquisa: Doenças infecciosas: problemática e estratégias de enfrentamento.

Orientadora: $\operatorname{Prof}^{a} \operatorname{Dr}^{a}$ CRISTINA MARIA GALVÃO

Ribeirão Preto

2004 
Autorizo a reprodução e divulgação total ou parcial deste trabalho, por qualquer meio convencional ou eletrônico, para fins de estudo e pesquisa, desde que citada a fonte.

Catalogação na publicação

Serviço de Documentação de Enfermagem

Escola de Enfermagem de Ribeirão Preto

Universidade de São Paulo

Poveda, Vanessa de Brito

Análise dos fatores predisponentes à infecção do sítio cirúrgico em gastrectomia/ Vanessa de Brito Poveda; orientadora: Cristina Maria Galvão - Ribeirão Preto, 2004.

Dissertação (Mestrado - Programa de Pós-Graduação em Enfermagem Fundamental do Departamento de Enfermagem Geral e Especializada, Linha de pesquisa: Doenças infecciosas: problemática e estratégias de enfrentamento) - Escola de Enfermagem de Ribeirão Preto da Universidade de São Paulo.

1. Infecção do sítio cirúrgico. 2. Fatores de risco. 3. Gastrectomia 
Vanessa de Brito Poveda

Análise dos fatores predisponentes à infecção do sítio cirúrgico em gastrectomia

Dissertação de mestrado apresentada à Escola de Enfermagem de Ribeirão Preto da Universidade de São Paulo, para obtenção do título de Mestre.

Linha de pesquisa: Doenças infecciosas: problemática e estratégias de enfrentamento.

Aprovado em:

\section{BANCA EXAMINADORA}

Profa $^{\text {Dra }}$ Cristina Maria Galvão

Professora Doutora do Departamento de Enfermagem Geral e Especializada da Escola de Enfermagem de Ribeirão Preto, Universidade de São Paulo. Orientadora. Julgamento: Assinatura:

Profa $^{\mathrm{a}} \mathrm{Dr}^{\mathrm{a}}$ Denise Andrade

Professora Doutora do Departamento de Enfermagem Geral e Especializada da Escola de Enfermagem de Ribeirão Preto, Universidade de São Paulo.

Julgamento: Assinatura

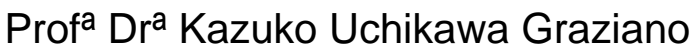

Professora Doutora do Departamento de Enfermagem Médico-Cirúrgica da Escola de Enfermagem, Universidade de São Paulo.

Julgamento: Assinatura: 
Na vida,

não vale tanto

o que temos

nem tanto importa

o que somos.

Vale o que realizamos

com aquilo que possuímos

e, acima de tudo,

importa

o que fazemos de nós.

Extraído do livro: "Caminhos", de Francisco Cândido Xavier. Ditado pelo Espírito Emmanuel 


\section{DEDICATÓRIA}

Aos meus pais, Everilda e Luiz,

Pelo exemplo de amor e fé, pelo apoio incondicional, minha eterna gratidão.

Aos meus irmãos, Fabiana e Tiago (in memoriam),

Que o amor nos una, sempre.

Ao César,

Pela presença, compreensão e apoio em todos os momentos. 


\section{AGRADECIMENTOS ESPECIAIS}

À Profa Dr $^{\mathrm{a}}$ Cristina Maria Galvão pela coragem em orientar-me nesta jornada. Obrigada pelo apoio, carinho e sensibilidade.

À Profa Dra Kazuco U. Graziano e Prof ${ }^{a}$ Dra $^{a}$ Denise Andrade, pelas importantes contribuições a este trabalho.

À Profa Dra $^{\mathrm{a}}$ Cláudia Benedita dos Santos pelo apoio e atenção na elaboração desta dissertação.

À Coordenação de Aperfeiçoamento de Pessoal de Nível Superior (CAPES) pelo financiamento deste estudo.

À Escola de Enfermagem de Ribeirão Preto, seus professores e funcionários, pela intensa contribuição não só em minha formação como profissional e na realização deste trabalho, mas na minha formação como um ser humano melhor.

A todos aqueles que direta e indiretamente contribuíram para a realização deste estudo. Muito obrigada. 


\section{SUMÁRIO}

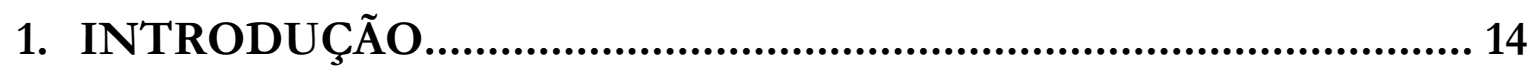

1.1 Breve histórico da Infecção Hospitalar...................................................17

1.2 O paciente cirúrgico e a infecção do sítio cirúrgico.................................. 21

2. OBJETIVOS.................................................................... 27

3. PROCEDIMENTO METODOLÓGICO.................................. 29

3.1 Construção e validação do instrumento.....................................................31

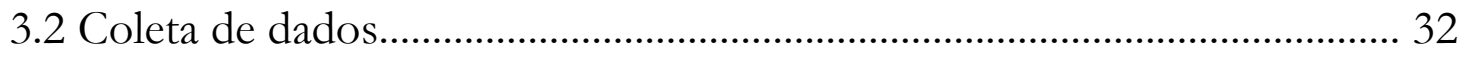

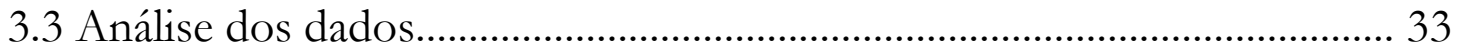

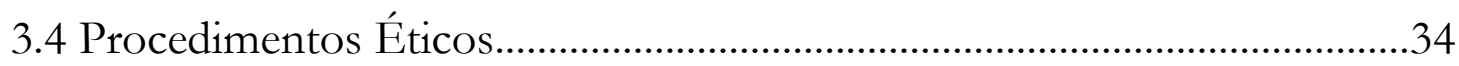

4. RESULTADOS E DISCUSSÃO................................................... 35

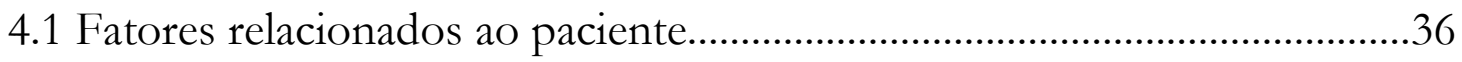

4.2 Fatores relacionados ao procedimento cirúrgico......................................43

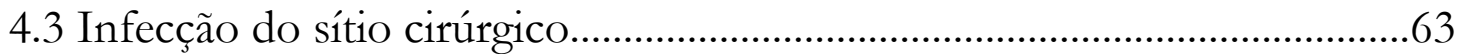

5. CONCLUSÕES........................................................................69 69

6. REFERÊNCIAS BIBLIOGRÁFICAS...................................... 74

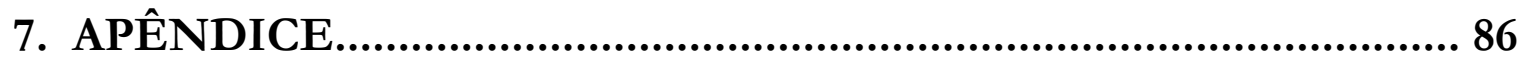

Apêndice A - Instrumento de Coleta de Dados (Parte 1).............................. 87

Apêndice B - Instrumento de Coleta de Dados (Parte 2).............................. 88 


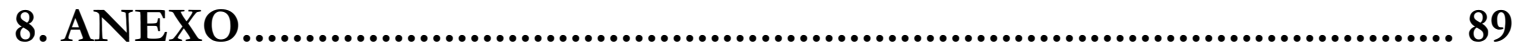

Anexo A - Aprovação do Comitê de Ética........................................................ 90 


\section{LISTA DE ABREVIATURAS E SIGLAS}

ANVISA Agência Nacional de Vigilância Sanitária

AORN Association of Perioperative Registered Nurses

APECIH Associação Paulista de Estudos e Controle de Infecção Hospitalar

ASQ Amplitude semi quartílica

ATBP Antiobioticoprofilaxia

CCIH Comissão de Controle de Infecção Hospitalar

CDC Centers for Disease Control and Prevention

CUCA Comissão de Uso e Controle de Antimicrobianos

EUA Estados Unidos da América

HDL High Density Lipoprotein Cholesterol

IH Infecção hospitalar

ISC Infecção do sítio cirúrgico

ITU Infecção do Trato Urinário

MRSA Staphylococcus aureus meticilino-resistente

NNISS National Nosocomial Infection System Surveillance

OSHA Occupational Safety and Health Association

PET Programa Especial de Treinamento

PVPI Polivinilpirrolidona lodo

SAME Serviço de Arquivo Médico e Estatístico

SENIC Study on the Efficacy of Nosocomial Infection Control

SESU Secretaria de Educação Superior

SPSS Statistical Package Social Science 


\section{LISTA DE TABELAS}

Tabela 1- Distribuição dos pacientes submetidos a gastrectomias em um hospital público, segundo a variável idade e a presença ou não de infecção do sítio cirúrgico. Ribeirão Preto, 2003

Tabela 2- Distribuição dos pacientes submetidos à gastrectomias em um hospital público, segundo o período de internação pré-operatório e a presença ou não de infecção do sítio cirúrgico. Ribeirão Preto, 2003

Tabela 3- Distribuição dos pacientes submetidos a gastrectomias em um hospital público, segundo o período de internação pós-operatório e a presença ou não de infecção do sítio cirúrgico. Ribeirão Preto, 2003

Tabela 4- Distribuição dos pacientes submetidos à gastrectomias em um hospital público, segundo o período de internação total e a presença ou não de infecção do sítio cirúrgico. Ribeirão Preto, 2003 50

Tabela 5- Distribuição dos pacientes submetidos a gastrectomias em um hospital público, segundo a duração da cirurgia e a presença ou não de infecção do sítio cirúrgico. Ribeirão Preto, 2003

Tabela 6- Distribuição dos pacientes submetidos a gastrectomias em um hospital público, segundo a utilização de dreno e o diagnóstico de infecção do sítio cirúrgico. Ribeirão Preto, 2003 .55

Tabela 7- Distribuição dos pacientes submetidos a gastrectomias em um hospital público, segundo o período entre a cirurgia e o diagnóstico de ISC. Ribeirão Preto, 2003 .66 


\section{RESUMO}

POVEDA, V.B. Análise dos fatores predisponentes à infecção do sítio cirúrgico em gastrectomia. 2004. 90 p. Dissertação (Mestrado) - Escola de Enfermagem de Ribeirão Preto, Universidade de São Paulo, Ribeirão Preto.

A infecção do sítio cirúrgico ocupa o segundo lugar em incidência dentro do ambiente hospitalar e está relacionada à vitória do microrganismo sobre a defesa do hospedeiro; envolve, também, interesses econômicos e sociais e se constitui num desafio aos profissionais de saúde. A presente investigação teve como objetivo identificar os fatores de risco relacionados à infecção do sítio cirúrgico, em paciente submetido à cirurgia eletiva de gastrectomia, potencialmente contaminada, na especialidade de Gastrocirurgia, no período compreendido entre 1998 a 2002, em um hospital público do interior paulista. Para tanto, realizou-se um estudo retrospectivo, por meio do levantamento de informações contidas nos prontuários médicos, utilizando-se para a análise estatística dos dados os testes não paramétricos: Mann-Whitney (variáveis quantitativas) e coeficiente de contingência (variáveis qualitativas). Em 181 casos investigados, detectou-se a ocorrência de infecção do sítio cirúrgico em 17 situações (9,4\%), sendo 23,5\% classificadas como infecção incisional superficial; 52,9\%, infecção incisional profunda e 23,5\%, infecção de órgão/espaço. Quanto às variáveis referentes ao período de internação pósoperatório, período de internação total, tempo de cirurgia, sondagem vesical de demora foram associadas à presença de infecção do sítio cirúrgico. Neste estudo não se verificou associação entre infecção do sítio cirúrgico e as variáveis referentes à idade, período de internação pré-operatório, utilização de dreno, sexo, raça, diagnóstico etilismo, tabagismo, presença de doenças crônicas, realização de tricotomia, antibioticoprofilaxia, anti-sepsia, tipo de cirurgia, transfusão sangüínea e focos infecciosos à distância.

Palavras-chave: infecção do sítio cirúrgico, fatores de risco, gastrectomia. 


\begin{abstract}
POVEDA, V.B. Analysis of predisposing factors for surgical site infection in case of gastrectomy. 2004. 90 p. Master's Thesis - University of São Paulo at Ribeirão Preto, College of Nursing, Ribeirão Preto.

Surgical site infection occupies the second place in terms of incidence in the hospital environment and is not only related to the victory of the microorganism on the defense of its host, but also includes economic and social interests. Moreover, it also constitutes a challenge to health professionals. This research aimed to identify the risk factors related to surgical site infection in patients submitted to a potentially contaminated elective gastrectomy, as a part of Gastric surgery, in the period between 1998 and 2002, at a public hospital in the interior of São Paulo, Brazil. Therefore, a transversal study was carried out by means of a medical record information survey, using the following non-parametric tests for statistical data analysis: Mann-Whitney (quantitative variables) and contingency coefficient (qualitative variables). Out of the 181 cases that were examined, the occurrence of surgical site infection was detected in 17 situations (9.4\%), 23.5\% of which were categorized as superficial incisional infection, 52.9\% as deep incisional infection and $23.5 \%$ as organ/space infection. The following variables were associated with the presence of surgical site infection: post-operative hospitalization period, total hospitalization period, surgery time, time to dwelling vesical catheter removal. No link could be found between surgical site infection and the variables age, pre-operative hospitalization period, drain usage, gender, race, alcoholism, smoking, history of chronic illnesses, trichotomy, antibiotic prophilaxis, antisepsis, kind of surgery, blood transfusion and distant infection sources.
\end{abstract}

Keywords: surgical site infection, risk factors, gastrectomy 


\section{RESUMEN}

POVEDA, V.B. Análisis de los factores predisponentes a infección del sitio quirúrgico en gastrectomía. 2004. 90 p. Disertación (Maestría) - Escuela de Enfermería de Ribeirão Preto, Universidad de São Paulo, Ribeirão Preto.

La infección del sitio quirúrgico es la segunda en términos de incidencia dentro del ambiente hospitalario e está relacionada no sólo a victoria del microorganismo sobre la defensa del hospedero, pero también incluye intereses económicos y sociales, además de constituir un desafío a los profesionales de salud. La finalidad de esta investigación fue la de identificar los factores de riesgo relacionados a la infección del sitio quirúrgico en paciente sometido a la cirugía electiva de gastrectomía, potencialmente contaminada, en la especialidad de Gastrocirugía, en el período entre 1998 y 2002, en un hospital público del interior de São Paulo, Brasil. Para eso, realizamos un estudio transversal, mediante la recopilación de informaciones contenidas nos prontuarios médicos. Para el análisis estadístico de los datos, utilizamos los testes no paramétricos: Mann-Whitney (variables cuantitativas) y coeficiente de contingencia (variables cualitativas). Entre 181 casos investigados, detectamos la ocurrencia de infección del sitio quirúrgico en 17 situaciones (9,4\%); sendo 23,5\% clasificadas como infección incisional superficial; 52,9\% infección incisional profunda y $23,5 \%$ de infección de órgano / espacio. Las variables período de internación postoperatorio, período de internación total, tiempo de cirugía, período de permanencia del catéter vesical a permanencia fueron asociadas a la presencia de infección del sitio quirúrgico. No fue verificada ninguna asociación entre la infección del sitio quirúrgico y las variables de edad, período de permanencia preoperatorio, utilización de dreno, género, raza, diagnóstico alcoholismo, tabaquismo, presencia de enfermedades crónicas, realización de tricotomía, profilaxis antibiótica, antisepsia, tipo de quirurgía, transfusión sanguínea y focos infecciosos a distancia.

Términos clave: infección del sitio quirúrgico, factores de riesgo, gastrectomía 
Durante a graduação, pela primeira vez, realizamos uma aproximação com a temática infecção hospitalar por meio da iniciação científica, pois no período de 1999-2001 participamos do Programa Especial de Treinamento (PET), subvencionado, no ano de 1999, pela Fundação Coordenação de Aperfeiçoamento de Pessoal de Nível Superior (CAPES) e a partir de 2000 pela Secretaria de Educação Superior (SESu) do Ministério da Educação.

No PET o aluno de graduação desenvolve atividades extracurriculares de ensino, pesquisa e extensão. E no contato com as atividades de pesquisa, inicialmente nos familiarizamos com o procedimento metodológico, tipos de estudo e, em seguida, passamos a desenvolver estudos na temática de nosso interesse, no caso infecção hospitalar, buscando pesquisadores que já desenvolviam trabalhos nessa mesma área.

Assim, desenvolvemos um primeiro estudo sobre infecção hospitalar, procurando identificar os fatores de risco para infecção do sítio cirúrgico presente em diferentes procedimentos cirúrgicos na especialidade de gastroenterologia, sem nos prendermos a uma análise das associações presentes, como uma forma de aproximação ao tema pelo qual já tínhamos interesse (POVEDA; GALVÃO; HAYASHIDA, 2003).

Dessa forma, nosso interesse e curiosidade foram aguçados, despertando o desejo de aprofundarmos o estudo da temática, buscando para isso a inserção no mestrado, dando continuidade ao estudo da graduação. Na pós-graduação, procuramos ampliar o conhecimento por meio das oportunidades oferecidas nas aulas teóricas, em leitura de artigos e discussões com profissionais, as quais contribuíram, sobremaneira, para o desenvolvimento do estudo que se segue. 
A curiosidade científica não foi o único estímulo para nossa aproximação com o tema, principalmente, considerando-se sua relevância para a assistência ao paciente cirúrgico. Vale destacar, que a contribuição do controle de infecção, especialmente, quando pautado no conhecimento científico, foi que nos motivou a realizar esta investigação.

Compete, pois, aos profissionais de saúde fornecer aos pacientes a proteção possível e necessária para que não desenvolvam problemas paralelos aos já existentes, que os prejudiquem tanto ou mais que os iniciais, fragilizando-os e gerando sentimentos de revolta, já que eles poderiam ter sido evitados.

Apesar de todo o avanço científico-tecnológico, a exemplo dos novos fármacos e do desenvolvimento de procedimentos menos invasivos, a infecção hospitalar figura ainda como um importante problema de saúde pública, não só pelos altos custos que Ihe são atribuídos e prevalência, mas também pela resistência bacteriana a diversos tipos de agentes antimicrobianos, dificultando ainda mais seu combate e alertando para a importância da prevenção e controle desta problemática.

O presente estudo tem como propósito aprofundar o conhecimento sobre os fatores de risco para ISC, tentando contribuir para a melhoria da assistência prestada ao paciente cirúrgico.

A seguir, apresentaremos tópicos a respeito da infecção hospitalar e da infecção do sítio cirúrgico. 


\subsection{Breve histórico da Infecção Hospitalar}

Podemos considerar que a infecção hospitalar tal como a conceituamos hoje, principiou-se quando passamos a reunir doentes, independentemente das moléstias, em locais sem condições de saneamento, ventilação ou cuidados dirigidos.

Com o passar do tempo, despertamos para os problemas advindos desta situação, ou seja, as infecções, tendo como uma das conseqüências, a morte. Assim, não podemos deixar de citar aqui, a sagacidade de pessoas como Ignaz Philipp Semmelweis, que reduziu a incidência de septicemia puerperal, que levava à morte centenas de mulheres, com a instituição de uma medida muito simples e atualmente reconhecida como fundamental na prevenção da infecção hospitalar, a lavagem das mãos (RABHAE; RIBEIRO FILHO; FERNANDES, 2000).

Nesse sentido, outras contribuições marcaram época, pois com a instituição de medidas adequadas de limpeza e organização do ambiente hospitalar, além do treinamento e supervisão dos responsáveis pelo cuidado, as enfermeiras, Florence Nightingale, em 1863, conseguiu tornar o ambiente hospitalar um lugar mais propício à cura, atuando no combate à propagação das infecções hospitalares (LACERDA, 2003b).

A estas descobertas brilhantes, devemos acrescentar a descrição da bactéria, por Van Leeuwenhoek (1632-1723); Pasteur, como o pioneiro na microbiologia, descrevendo a fermentação e os microrganismos e desenvolvendo o conceito de inoculação protetora, sendo que, em 1861, o sucesso de seus experimentos fez cair a teoria da geração espontânea (HEINZELMANN; SCOTT; LAM, 2002).

Continuando, Joseph Lister introduziu a anti-sepsia no tratamento de feridas e na execução dos procedimentos cirúrgicos, utilizando o fenol; Robert Koch 
demonstrou convincentes evidências da origem das infecções em feridas e a patogenicidade dos organismos pirogênicos ao identificar a etiologia da tuberculose, anthrax e da cólera (HEINZELMANN; SCOTT; LAM, 2002).

Porém, a partir do século XVIII, quando o corpo passa a ser valorizado como objeto de trabalho, percebe-se a transformação dos hospitais, de um local em que os pobres eram internados, inclusive para morrer, para um local de tratamento e cura (LACERDA; EGRY, 1997).

Devemos salientar que, no fim do século XVIII, os cuidados higiênicos da população eram ainda bastante precários, sendo as infecções comunitárias graves. No que se referem às infecções hospitalares, estas já existiam, porém eram consideradas "fenômenos naturais", como a morte materna por sepse, até a perspicácia de Semmelweis provar o contrário (NEVES, 1993).

A necessidade de mão-de-obra saudável levou o governo britânico a adotar diversas atitudes, em meados do século XIX, como a criação de programas que atendessem a patologias específicas, dentre elas, a tuberculose, doenças venéreas, cardíacas e a implantação de programas específicos, como os direcionados à assistência materno-infantil, além de melhorias nas condições sanitárias, como sistemas de abastecimento de água e esgoto (FERNANDES, 2000a).

A partir do momento que o corpo passa a ser visto como fonte de produção no modelo capitalista, acontece a valorização do cirurgião, pois no período medieval, este não era considerado um profissional "nobre” (LACERDA; EGRY, 1997).

Uma outra tentativa no sentido de manter a mão-de-obra saudável foi o esforço em se aprimorarem os antimicrobianos, como o advento das sulfonamidas, que solucionaram diversos problemas vigentes na época, motivo pelo qual a penicilina não recebeu a devida atenção, além das dificuldades que a Primeira 
Guerra Mundial impôs para o seu aprimoramento. Mais tarde, ao tentarem solucionar as desvantagens da penicilina, acabaram por descobrir a primeira de uma série de drogas do grupo dos aminoglicosídeos (estreptomicina) e, a partir daí, desenvolveuse uma série de novos antibióticos (FERNANDES, 2000a).

Assim, considerando as relevantes descobertas da medicina, particularmente no combate à infecção, chegamos ao século $X X$, quando se criaram comissões para auxiliarem no seu combate.

Nos Estados Unidos da América (EUA), em 1958, criou-se a Comissão de Controle de Infecção Hospitalar $(\mathrm{CClH})$, seguindo recomendação da Associação América dos Hospitais, provavelmente, devido ao aumento do número de estafilococcias hospitalares naquele período. Com isso, os hospitais teriam um instrumento eficaz para apurar as infecções desenvolvidas na instituição, que verificaria se estas decorriam ou não da negligência de boas condutas, beneficiando pacientes e fornecendo defesa aos médicos, em casos de ações legais por negligência, imperícia ou imprudência (NEVES, 1993).

Em 1975, esta recomendação tornou-se uma exigência, em virtude de uma ação judicial contra um clínico que, ao atender uma estudante de 18 anos que fraturara a perna em um jogo de futebol, após 40 horas da aplicação do aparelho de gesso, soube que a paciente referia dor localizada e mau cheiro e nada fez, inicialmente, porém ao abrir o gesso, percebeu extensa lesão necrótica, que não foi debridada. A paciente então solicitou alta, internando-se em outro hospital, onde o cirurgião em virtude do quadro amputou-lhe a perna. O processo tramitou até a Suprema Corte dos EUA, sendo o médico responsável pelo atendimento inicial e o hospital obrigados a pagarem pesada indenização (NEVES, 1993). 
No Brasil, a preocupação com a infecção hospitalar (IH) efetivamente surgiu a partir da década de 80, com a morte de Tancredo Neves, que teve sua condição clínica agravada pela infecção; a partir daí, incentivaram-se ações governamentais por meio de cursos, manuais e portarias. Na década de 90, apesar das tentativas de implementação de controle da infecção, dados da Coordenadoria de Controle de IH do Ministério da Saúde demonstraram pouca efetividade das ações, estimando-se que apenas 10\% dos hospitais haviam criado comissões para esse fim (LACERDA, 2003a).

Ainda na década de 90, surgiu o interesse por eventos científicos voltados ao controle de $\mathrm{IH}$, o que fez crescer o número de estudos para aperfeiçoamento dos métodos de vigilância epidemiológica. Na segunda metade desta mesma década, houve a necessidade de se controlar a qualidade dos hospitais, que cresceram, tendo os profissionais e as instituições de saúde começado a buscar modelos operacionais.

Assim, a produção científica nacional, desde a década de 50, vê-se voltada predominantemente para o ambiente (procedimentos de anti-sepsia, esterilização, desinfecção, higiene, áreas de risco, fluxo de pessoal, material), mas a partir da década de 70, destaca-se a multicausalidade, atribuindo-se as infecções não mais apenas ao ambiente, mas também à susceptibilidade individual e à introdução de novas tecnologias. Quando na década de 80 a $\mathrm{IH}$ evoluiu em quantidade e gravidade, chamando a atenção dos veículos de comunicação, a produção científica nacional manifestou-se em forma de denúncias, evidenciando a necessidade de organização da $\mathrm{CCIH}$, e, assim, iniciaram-se as principais ações governamentais, validando e padronizando produtos, tais como: desinfetantes, anti-sépticos e esterilizantes. Na década de 90, com a implantação da CCIH nos hospitais, a 
atenção voltou-se para os métodos de Vigilância Epidemiológica, na tentativa de prevenção e controle da IH (LACERDA, 2002).

\subsection{O paciente cirúrgico e a infecção do sítio cirúrgico}

Envidaram-se muitos esforços para que conseguíssemos obter os avanços que hoje desfrutamos, os quais auxiliam o combate à infecção.

Em relação ao controle de infecção, nós, os profissionais da saúde, devemos ainda desmistificar muitas atitudes vigentes (LAFRENIÈRE et al., 2001), aprendendo a questionar cada vez mais a nossa prática, bem como todos os aspectos que direcionam ou sustentam nosso desempenho profissional. É assim, pela busca de fundamentação teórica de nossos atos e através do desenvolvimento de pesquisas e da utilização de seus resultados, que conseguiremos transpor os obstáculos.

Outro aspecto a ser enfocado é a formação dos profissionais de saúde. Conceitos devem ser revisados e ações implementadas, no sentido de minimizarem o sofrimento daqueles que desenvolvem infecção, por meio da humanização do ato médico e da contratação pelos hospitais de número adequado de profissionais frente à sua demanda. Nesse contexto, o trabalho da enfermagem é imprescindível para o controle da infecção hospitalar (NEVES, 1994), que, atualmente, é definida como "aquela adquirida após a admissão do paciente, e que se manifesta durante a internação ou após a alta, quando puder ser relacionada com a internação ou procedimentos hospitalares" (BRASIL, 1998).

O Centers for Disease Control and Prevention (CDC), dos EUA, recomenda a substituição do termo infecção da ferida operatória por infecção do sítio cirúrgico (ISC), dado que nem toda infecção relacionada ao procedimento cirúrgico ocorre na 
ferida propriamente dita, podendo também atingir órgãos e espaços manipulados durante o procedimento. O diagnóstico epidemiológico é feito observando-se os seguintes critérios: o surgimento da infecção deve acontecer em até 30 dias após o procedimento, ou em casos de implantes de próteses em até 1 ano (ASSOCIAÇÃO PAULISTA DE ESTUDOS E CONTROLE DE INFECÇÃO HOSPITALAR - APECIH, 2001).

De acordo com Grinbaum (1997), dados do Study on the Efficacy of Nosocomial Infection Control (SENIC) demonstram que a infecção do sítio cirúrgico é superada, em termos de incidência, apenas pela infecção do trato urinário.

Mangram et al. (1999) ressaltam que, entre os pacientes cirúrgicos, a ISC é a infecção hospitalar mais comum, sendo que um terço delas é confinada à incisão, e dois terços envolvem órgãos e espaços abordados durante o procedimento. Quando os pacientes cirúrgicos com ISC morrem, 77\% destas mortes estão relacionadas à infecção, e a maioria (93\%) envolve órgãos e espaços manipulados na cirurgia.

Para o desencadeamento do processo infeccioso, deverá ocorrer a interação entre os fatores relacionados ao agente agressor, às características do hospedeiro, bem como à resposta aos estímulos desencadeadores do distúrbio (LACERDA, 2003a).

A contaminação microbiana do sítio cirúrgico é um aspecto precursor da infecção, no entanto, o local contaminado deve conter um inóculo maior que $10^{5}$ microrganismos por grama de tecido. Ressaltamos que a maioria das ISC é causada pela microbiota endógena do paciente, oriunda freqüentemente da pele, mucosas e vísceras (MANGRAM et al., 1999).

A microbiota hospitalar pode estar presente no ambiente e/ou nos profissionais de saúde (os quais podem levar esta contaminação ao paciente, por 
meio de suas mãos ou pelos instrumentais), composta não somente de microrganismos primários ${ }^{1}$, mas também de microbiota humana, sendo que esta última, ao sofrer alterações, conseqüentes da própria evolução tecnológica, acaba ocasionando infecções (LACERDA; EGRY, 1997).

Para a aquisição de infecção, o microrganismo deve vencer as barreiras antiinfecciosas do hospedeiro, levando ao desequilíbrio entre parasita e hospedeiro. A pele íntegra constitui uma barreira mecânica contra a invasão de microrganismos, além de secretar vários agentes antimicrobianos, porém, no procedimento cirúrgico, é a primeira barreira a ser quebrada (FERNANDES; RIBEIRO FILHO, 2000c).

Para o Ministério da Saúde, a ISC pode ser classificada conforme o potencial de contaminação da ferida operatória, em:

1. Cirurgias limpas: são aquelas realizadas em tecidos estéreis ou passíveis de descontaminação, na ausência de processo infeccioso e inflamatório local ou falhas técnicas grosseiras, cirurgias eletivas com cicatrização de primeira intenção e sem drenagem aberta. Cirurgias em que não ocorram penetrações nos tratos digestivo, respiratório ou urinário;

2. Cirurgias potencialmente contaminadas: são aquelas realizadas em tecidos contaminados por flora microbiana pouco numerosa ou em tecidos de difícil descontaminação, na ausência de processo infeccioso e inflamatório e com falhas técnicas discretas no transoperatório. Cirurgias limpas com drenagem aberta enquadram-se nesta categoria. Ocorre penetração nos tratos digestivo, respiratório ou urinário sem contaminação significativa;

3. Cirurgias contaminadas: são aquelas realizadas em tecidos recentemente traumatizados e abertos, colonizados por flora bacteriana abundante, cuja descontaminação seja difícil ou impossível, bem como todas aquelas em que tenham ocorrido falhas técnicas grosseiras, na ausência de supuração local. Presença de inflamação aguda na incisão e cicatrização de segunda intenção, grande

\footnotetext{
${ }^{1}$ São aqueles “que não pertencem à flora humana normal e que causam infecção no homem” (LACERDA; EGRY, 1997).
} 
contaminação a partir do tubo digestivo. Obstrução biliar ou urinária também se incluem nesta categoria;

4. Cirurgias infectadas: são todas as intervenções cirúrgicas realizadas em qualquer tecido ou órgão, em presença de processo infeccioso (supuração local) e/ou tecido necrótico (Brasil, 1998).

Além do inóculo, diversos fatores predispõem o desenvolvimento de ISC, que podem estar relacionados ao paciente, como idade, presença de doenças como diabetes mellitus; e ao procedimento cirúrgico, como a tricotomia, anti-sepsia e duração da cirurgia (RABHAE; RIBEIRO FILHO; FERNANDES, 2000).

Assim, estes fatores predisponentes, também nomeados fatores de risco, são entendidos como "características que estão associadas a um maior risco de adoecer". Tais fatores de risco podem ser herdados, sendo, portanto, de origem genética, como a presença de genes que aumentam o risco para o desenvolvimento de determinadas doenças, por exemplo, alguns tipos de câncer; sociais, como a mudança de rotinas diárias, e comportamentais, como o uso excessivo de bebidas alcoólicas e do tabaco (FLETCHER et al., 1996).

O fator social relacionado ao desenvolvimento de ISC repercute na vida do indivíduo acometido, seja porque um período maior de hospitalização onera não só os custos da instituição, e dos serviços da comunidade, como também, porque ao permanecer mais dias hospitalizado retarda seu retorno às atividades diárias, deixando-o mais dias afastado do trabalho (REILLY et al., 2001).

A literatura tem documentado a associação entre ISC e hospitalizações, sendo que o desenvolvimento de infecções acaba incrementando os índices de novas hospitalizações, aumentando significativamente, dentre outros agravos, os custos do cuidado em saúde (FIELDS, 1999). Também os gastos da previdência social com o paciente que desenvolve ISC e que se hospitaliza novamente para 
tratamento das seqüelas são acentuados, gerando custos elevados para a instituição hospitalar (POULSEN et al., 1994).

Por esse motivo, ressaltamos a importância da vigilância pós-alta, pois os casos de infecção seriam subestimados se esta não existisse, como podemos verificar no estudo de Lemos, Oliveira e Sousa (1999), onde os autores identificaram que $32,5 \%$ dos casos de infecção foram diagnosticadas no ambulatório durante o retorno do paciente, enquanto Oliveira et al. (2002) verificaram que 62,9\% das infecções do sítio cirúrgico foram notificadas no ambulatório de egressos. A vigilância pós-alta não detecta apenas os casos de infecção que se desenvolvem fora do ambiente hospitalar, permite, também, a avaliação das rotinas, educação continuada, e a possibilidade de identificação de surtos.

A Associação Paulista de Estudos e Controle de Infecção Hospitalar, fundamentada no SENIC, desenvolvido pelo CDC, enfatiza que o estudo dos aspectos relacionados à incidência, morbi-letalidade e custos da ISC poderiam auxiliar na prevenção, em até 20\%, por meio da vigilância epidemiológica associada à implementação de programas de controle (APECIH, 1995).

Portanto, o controle de infecção do sítio cirúrgico abrange, também, interesses econômicos, que visem reduzir custos para as instituições e sociedade; interesses sociais, demonstrados pela necessidade da volta, o mais rápido possível, ao mercado de trabalho, além de constituir um desafio aos profissionais de saúde que atuam no combate a esta iatrogenia da assistência à saúde.

Frente ao exposto, entendemos que é de extrema relevância que os profissionais de saúde compreendam os fatores que influenciam a incidência de ISC para implementação de ações efetivas que minimizem os riscos de infecções, contribuindo para a qualidade da assistência prestada ao paciente cirúrgico e que os 
profissionais do controle de IH (vinculados a Comissão de Controle de Infecção Hospitalar) tenham acesso a estudos que Ihes ofereçam subsídios que possibilitem reflexões sobre a sua atuação frente às medidas de prevenção e controle de $\mathrm{IH}$. 


\section{Objetivo Geral}

œ Analisar os fatores de risco relacionados à infecção do sítio cirúrgico em paciente submetido à cirurgia eletiva de gastrectomia, potencialmente contaminada, na especialidade de Gastrocirurgia, no período compreendido entre 1998 a 2002, em um hospital público do interior paulista.

\section{Objetivos Específicos}

œ Caracterizar o paciente submetido à gastrectomia eletiva em um hospital público do interior paulista;

œ Identificar a freqüência de infecção do sítio cirúrgico;

caldentificar os fatores de risco relacionados ao paciente e ao procedimento cirúrgico. 
A presente investigação é um estudo retrospectivo com abordagem quantitativa e delineamento de pesquisa não-experimental, sendo este delineamento utilizado quando o pesquisador pretende elaborar "o quadro de um fenômeno ou explorar acontecimentos, pessoas ou situações à medida que eles ocorrem naturalmente". Nesse tipo de delineamento, o pesquisador não manipula uma ou mais variáveis, mas explora relações ou diferenças (LOBIONDO-WOOD; HABER, 2001, p.111).

Quanto à definição de estudos retrospectivos, são aqueles em que a variável dependente já sofreu o efeito da variável independente, e sobre os quais o pesquisador tenta construir a seqüência dos eventos, ligando os acontecimentos presentes ao passado por meio de registros (LOBIONDO-WOOD; HABER, 2001; MEININGER, 1998).

Gil (2002, p.49) refere que a diferença mais importante entre o estudo retrospectivo e o experimental, é que, no primeiro, o investigador não tem controle sobre a variável independente, pois esta já ocorreu; assim, nesse tipo de pesquisa, o pesquisador procura "identificar situações que se desenvolveram naturalmente e trabalhar sobre elas como se estivessem submetidas a controles". Esta modalidade de estudo permite constatar a existência de relação entre as variáveis.

O local selecionado para o estudo foi um hospital regional, de nível terciário, situado no interior do estado de São Paulo e destinado ao ensino, pesquisa e assistência. Composto por ambulatórios, unidades de internação, laboratórios e serviços especializados, administração, unidades de apoio, dentre outros setores. Conta com 847 leitos, atendendo a demanda proveniente de 21 cidades da região, sendo responsável por 20\% destas internações. Segundo informações do Grupo de Avaliação de Desempenho (GAD, 2003), no ano de 2003, o hospital manteve em 
seus quadros 4.681 servidores, e ainda, 503 médicos residentes, 84 aprimorandos e 234 docentes, foi responsável por 29.367 cirurgias e 32.807 internações, tendo a especialidade de gastrocirurgia realizado 572 procedimentos cirúrgicos nesse mesmo ano.

Assim, visando desenvolver uma pesquisa que analisasse os fatores predisponentes à infecção do sítio cirúrgico em gastrectomia, elaboramos o presente estudo, que dividimos em três fases, a saber: a primeira constituiu-se na construção e validação do instrumento para a coleta de dados; a segunda, na coleta de dados propriamente dita, e a terceira e última, na análise dos dados.

\subsection{Construção e validação do instrumento}

Iniciamos o estudo solicitando ao órgão de documentação médica a listagem dos pacientes submetidos a gastrocirurgias eletivas, no período compreendido entre janeiro de 1998 a dezembro de 2002. A partir desta listagem, procuramos identificar qual a cirurgia mais freqüente na especialidade estudada, destacando-se a colecistectomia por videolaparoscopia, que se trata de um procedimento minimamente invasivo e, muitas vezes, realizado em âmbito ambulatorial. Os pacientes que se submetem a esse tipo de cirurgia não sofrem hospitalizações longas e estão, geralmente, em condições favoráveis de saúde, ou seja, não têm associação de outras doenças de base. Frente ao exposto, escolhemos a segunda cirurgia mais freqüente, a gastrectomia, independentemente da técnica cirúrgica utilizada, por se adequar melhor ao propósito deste estudo.

Para o alcance do objetivo proposto para o presente estudo, elaboramos um instrumento, que foi submetido à análise, para validação aparente e de conteúdo, de 
três juízes (um docente de universidade e dois enfermeiros de hospital público) com experiência na temática investigada. Após análise do instrumento, sugeriram alterações quanto à compreensão dos itens, na forma de apresentação e alcance do objetivo traçado, que foram, na sua maioria, acatadas pela pesquisadora.

O instrumento de coleta de dados, constituído por duas partes, continha na primeira informações relativas aos fatores de risco relacionados ao paciente e ao procedimento cirúrgico (APÊNDICE A - parte 1) e na segunda constavam os critérios diagnósticos de infecção, tendo a pesquisadora seguido para sua elaboração o que Mangram et al. (1999) preconizaram (APÊNDICE A - parte 2).

Após a validação aparente e de conteúdo, realizamos o teste piloto utilizando 10 prontuários médicos, os quais não incluímos na coleta de dados propriamente dita, para verificar a adequação do instrumento frente à mensuração do pretendido.

\subsection{Coleta de dados}

Ao todo, solicitamos 253 prontuários médicos, que eram separados a partir de listagens previamente agendadas no Serviço de Arquivo Médico (SAME), onde realizamos a coleta de dados.

Os prontuários não encontrados na primeira listagem solicitada, incluímos novamente em outras listagens, por até três vezes, mesmo assim, não pudemos realizar a revisão de 12 prontuários, pois, de acordo com informações do arquivo médico, estes estariam sendo utilizados no atendimento aos pacientes, ou em posse de algum médico do hospital. Excluímos os prontuários cujas cirurgias foram realizadas em caráter de urgência e as em que as propostas diferiam das realizadas, 
neste caso eram propostas gastrectomias, e realizado outros tipos de procedimento, totalizando 60 prontuários médicos.

Assim, dos 253 prontuários médicos solicitados ao SAME, 181 estavam de acordo com os critérios de inclusão ao estudo, ou seja, os pacientes foram submetidos a gastrectomias eletivas no período compreendido entre janeiro de 1998 a dezembro de 2002, cujos prontuários médicos estavam disponíveis no SAME do hospital escolhido para o estudo. Após a seleção dos prontuários, realizamos a coleta de dados nos meses de maio, junho e julho de 2003.

Destacamos que, na presente investigação analisamos, apenas as cirurgias eletivas, embora exista carência de estudos que comprovem o fato, em cirurgias consideradas emergenciais, geralmente não a tempo de compensar doenças de base, avaliar focos infecciosos à distância ou estado nutricional do paciente, o profissional pode cometer descuidos na técnica e na preparação do paciente, expondo-o a maior probabilidade de desenvolver infecção, pois "quando o risco de morte é iminente, a infecção passa a ser um tributo que a equipe de saúde paga para manter a vida do paciente" (RABHAE; RIBEIRO FILHO; FERNANDES, 2000).

\subsection{Análise dos dados}

Analisamos os resultados segundo a metodologia proposta, utilizando para as variáveis quantitativas contínuas, como idade, período de internação pré-operatório e pós-operatório, período total de internação, duração da cirurgia, sondagem vesical de demora e utilização de dreno, os testes de Levene e Kolmogorov-Smirnov, que mostraram, no caso de algumas variáveis, não haver normalidade e homogeneidade 
de variâncias. Sendo assim, optamos pela utilização do teste não paramétrico MannWhitney para testar as possíveis associações entre os grupos.

Para as variáveis qualitativas (categóricas): sexo, raça, diagnóstico, etilismo, tabagismo, presença de doenças crônicas, realização de tricotomia, antibioticoprofilaxia, anti-sepsia, tipo de cirurgia, transfusão sangüínea e outras infecções associadas, aplicamos os coeficientes de contingência.

Procurando dar maior rigor à análise dos dados, dada a diferença numérica entre os grupos com ou sem infecção, instituímos o $\alpha=0,01$ como nível de significância. Analisamos os dados através do software Statistical Package Social Science (SPSS 1.0).

\subsection{Procedimentos Éticos}

Este projeto de pesquisa foi submetido à apreciação do Comitê de Ética em Pesquisa (ANEXO A) do hospital selecionado, de acordo com a Resolução 196/96 do Conselho Nacional de Saúde, que regulamenta a pesquisa em seres humanos (BRASIL, 1996), sendo dispensado da aplicação do termo de consentimento livre e esclarecido, já que a pesquisadora coletou os dados nos prontuários médicos de cada paciente. 
Assim, o grupo de estudo foi composto por 181 prontuários médicos, pois estes atendiam aos critérios de inclusão da presente investigação.

Para atingir os objetivos propostos, optamos por dividir os dados em tópicos, de acordo com a organização apresentada no instrumento de coleta de dados.

\subsection{Fatores relacionados ao paciente}

Para a realização desta investigação, selecionamos 181 pacientes submetidos a gastrectomias eletivas, no período compreendido entre janeiro de 1998 a dezembro de 2002, cujos prontuários médicos estavam disponíveis no SAME do hospital escolhido para o estudo.

Deste grupo, 65 indivíduos eram do sexo feminino e 116 do masculino, sendo 140 da raça branca, 23 mulatos, 15 negros e 3 indivíduos da raça amarela. Do total da amostra (181), 149 (82,3\%) sujeitos apresentaram diagnóstico predominantemente oncológico.

$\mathrm{Na}$ análise das variáveis qualitativas, realizada com o teste coeficiente de contingência, não associamos nenhuma das variáveis como fator predisponente a ISC.

Observamos que, dentre os sujeitos investigados (181), 164 não desenvolveram ISC e 17 deles desenvolveram-na, sendo 15 destes do sexo masculino e apenas 2, do feminino. Esse tipo de cirurgia é realizada, em maior quantidade, em indivíduos do sexo masculino, porém não podemos considerar o sexo isoladamente como fator de risco para infecção, já que o câncer gástrico, diagnóstico prevalente neste estudo, é o primeiro em freqüência no homem e o terceiro na mulher (após mama e colo de útero), estando associado a fatores 
dietéticos (consumo freqüente de alimentos enlatados, salgados e defumados) e à contaminação pelo Helicobacter pylori (GAMA-RODRIGUES; FORONES, 1999).

A raça branca predominou, apresentando 16 casos de infecção, tendo 12 destes, diagnóstico médico oncológico.

Rabhae; Ribeiro Filho e Fernandes (2000) afirmam que os dados são escassos para mostrar a influência da raça nos índices de ISC, embora pareça não haver alteração nas taxas de infecção.

Quanto ao sexo, a literatura carece de artigos que comprovem estatisticamente este fator como de risco para incremento das taxas de infecção. A esse respeito, estudo de Lilienfield et al. (1988) identificou uma relação moderada entre o sexo feminino e a ocorrência de infecção pós-cirurgia cardíaca.

Cabtree et al. (1999) em estudo tipo coorte com 892 pacientes, quando analisaram o papel do gênero entre pacientes hospitalizados e tratados por infecção em diversos sítios, concluíram que o gênero não parece ser preditivo para mortalidade.

Dos sujeitos participantes deste estudo, 25,4\% eram aposentados; 22,6\% realizavam atividades ligadas a serviços domésticos (donas de casa e empregadas domésticas); 12,1\% eram ligados a atividades agrícolas; 2,2\% estavam desempregados e os demais trabalhavam em ocupações diversas (30,9\%). Em uma parcela do grupo (6,6\%), não localizamos em seus prontuários dados sobre a atividade profissional.

Doenças crônicas, como diabetes mellitus, obesidade e hipertensão arterial atingiram aproximadamente $46 \%$ do grupo, sendo que, em 6 casos onde houve ISC, os indivíduos tinham doenças crônicas associadas ao problema de base. 
Heinzelmann; Scott e Lam (2002) relatam que a presença de diabetes mellitus, especialmente quando não controlada, tem sido apontada como fator contribuidor para ISC, resultante de distúrbios na matriz das proteínas do colágeno, e da disfunção dos neutrófilos na aderência, quimiotaxia, fagocitose e morte intracelular. Em adição a isto, referem que a cetoacidose diabética diminui a resposta celular à inflamação, podendo tornar o sítio cirúrgico um local favorável ao crescimento bacteriano.

Estrada et al. (2003), ao analisarem 1.574 pacientes, sugerem que aqueles que apresentarem hiperglicemia no pré-operatório tendem a ter maior mortalidade, maior risco de desenvolver ISC e ficam mais dias hospitalizados no pós-operatório, gerando, portanto, maior custo à instituição.

Matsa et al. (2001) afirmam que a combinação entre diabetes mellitus, sexo feminino e obesidade foi associada à infecção incisional profunda de esterno. Quanto a Zerr et al. (1997), os autores demonstraram que a manutenção dos níveis de glicose sangüínea em cirurgias cardíacas, menor que 200 mg/dl, reduz a incidência de ISC no pós-operatório. Em decorrência deste estudo, Furnary et al. (1999), ao admitirem que diabetes mellitus é fator de risco para infecção profunda do esterno em pacientes submetidos a cirurgias cardíacas, elaboraram um protocolo de infusão de insulina (grupo controle: administração subcutânea de insulina, e o grupo de estudo: administração endovenosa de insulina) para controlar os níveis de glicose no pré-operatório, analisando, de maneira prospectiva, 2.467 pacientes. Concluíram que a infusão endovenosa de insulina reduz significativamente os níveis de glicose sangüínea, e também os índices de ISC.

A obesidade foi apontada como fator de risco para infecções, a razão seria a menor vascularização do tecido adiposo, aliada à duração dos procedimentos e à 
exposição de uma área maior à contaminação, com a possibilidade de formação de espaços mortos e a utilização de sutura subcutânea para fechá-los (RABHAE; RIBEIRO FILHO; FERNANDES, 2000).

Apesar de a obesidade ter sido apontada como fator de risco para diversos tipos de complicações, Dindo et al. (2003) indicam que a obesidade sozinha não deve ser considerada fator de risco para infecção, enquanto Kim et al. (2003) concluíram que obesos e não obesos têm a mesma chance de complicações pósoperatórias, embora os obesos tenham maior risco para infecção.

Olsen et al. (2002) procuraram determinar as diferenças relativas a fatores de risco para o desenvolvimento de infecção profunda ou superficial, ao estudarem 1980 pacientes submetidos a cirurgias cardíacas. Constataram aumento de infecções profundas em pacientes obesos e diabéticos, quando comparados aos não obesos e também diabéticos.

Outro aspecto interessante a ser discutido, levantado por Delgado Rodriguez et al. (2002), refere-se à relação existente entre ISC e baixos níveis séricos de albumina e colesterol (HDL- high density lipoprotein cholesterol).

Canturk et al. (2002), ao analisarem o papel do colesterol total e HDL em 480 pacientes pós-cirúrgicos, concluíram que existe associação entre baixos níveis de HDL e infecção hospitalar, como a ISC, e também infecções pulmonares, sugerindo que os parâmetros avaliados são preditores do risco de infecção.

Malone et al. (2002), reanalisando os fatores de risco, além de concluírem que o diabetes mellitus é realmente um significante fator predisponente à ISC, atentam ainda para o aspecto nutricional, confirmando uma associação estatisticamente significante entre desnutrição e infecção e demonstrando uma incidência de 6,9\% de desnutridos entre pacientes pré-operatórios. 
Dentre os sujeitos investigados nesta pesquisa, verificamos que $33,1 \%$ consumiam bebidas alcoólicas; 59,1\% não faziam uso delas e 7,7\% relatavam não mais consumi-las. Em relação ao tabagismo, 43,6\% dos sujeitos eram tabagistas; 37,5\%, não tabagistas e 18,8\%, ex-tabagistas. Quanto aos pacientes que desenvolveram infecção, 8 eram tabagistas, 6 não fumavam e 3, ex-tabagistas. No que se refere ao etilismo, 8 faziam uso de bebidas alcoólicas regularmente, 8 não faziam uso e 1 era ex-etilista.

Tonnesen; Schütten e Jorgensen (1987) ao analisarem 279 pacientes submetidos a cirurgias eletivas de ressecção de cólon e reto ou amputação de reto, quanto ao consumo de álcool, verificaram que o maior número de complicações foi preponderante no grupo que fazia uso de álcool, em quantidade maior ou igual a 60 gramas por dia.

Estudo prospectivo, que investigou 229 pacientes submetidos a histerectomias eletivas, mostrou que, entre os consumidores pesados de álcool, ocorreu maior morbidade pós-operatória, maior estada hospitalar, infecção do sítio cirúrgico, cistite, pneumonia e abscesso vaginal, quando comparados àqueles que faziam uso de bebida alcoólica em menor quantidade (FELDING; JENSEN; TONNESEN, 1992). Rantala; Lehtonen e Niinikoski (1997) concluíram que o álcool é um importante fator de risco para ISC e deve ser levado em consideração ao se determinar a susceptibilidade individual do paciente.

Delgado Rodrigues et al. (2003b) alertam que o consumo excessivo de álcool constitui fator predisponente para o desenvolvimento de muitas doenças infecciosas, particularmente as doenças pulmonares, tendo concluído que o consumo pesado de álcool, em homens (mais que $108 \mathrm{~g} / \mathrm{dia}$ ), aumenta o risco para todos os tipos de 
infecções hospitalares e os índices de ISC, em cirurgia geral. No entanto, o consumo de álcool não foi relacionado à prevalência de ISC pós-alta hospitalar.

Quanto ao tabagismo, Jones e Triplett (1992) observaram maior incidência de ISC nos casos de fumantes submetidos a cirurgias buco-maxilares. Para Mangram et al. (1999), este fator é predisponente para ISC, em cirurgias que envolvam o esterno e o mediastino. Sorensen et al. (2002), ao analisarem 425 pacientes submetidos a mastectomias, concluíram que independentemente de outros fatores de risco, o tabagismo foi associado ao desenvolvimento de ISC e a outros tipos de complicações específicas, nesse tipo de cirurgia.

Apesar dos índices de ISC serem geralmente menores em cirurgias ambulatoriais, mesmo assim o hábito de fumar está relacionado ao aumento do risco para o desenvolvimento deste tipo de infecção, fazendo crescer o número de complicações pós-operatórias (MYLES et al. 2002). Em contrapartida, no estudo de Delgado Rodriguez et al. (2003a), concluíram que o fumo não está associado à ISC, ao analisarem pacientes de um serviço de cirurgia geral, mas está relacionado ao aumento da mortalidade intra-hospitalar, admissão dos pacientes em unidade de terapia intensiva e infecções do trato respiratório.

Holt (1987) chama atenção para o fato que o término à exposição ao tabaco, em animais experimentais, foi associado à restituição das funções imune e inflamatória normais.

Em relação à idade, $26,5 \%$ dos sujeitos investigados em nosso estudo estavam na faixa etária dos 61 a 70 anos; 22,6\% na faixa dos 51 aos 60 anos e 18,8\% possuíam entre 71 e 80 anos de idade (TABELA 1). 
Tabela 1- Distribuição dos pacientes submetidos a gastrectomias em um hospital público, segundo as variáveis idade (anos) e a presença ou não de infecção do sítio cirúrgico. Ribeirão Preto, 2003

\begin{tabular}{|c|c|c|c|c|c|c|}
\hline \multirow[t]{2}{*}{ Idade (anos) } & \multicolumn{2}{|c|}{ Sem infecção } & \multicolumn{2}{|c|}{ Com infecção } & \multicolumn{2}{|c|}{ Total } \\
\hline & $\mathbf{N}$ & $\%$ & $\mathbf{N}$ & $\%$ & $\mathbf{N}$ & $\%$ \\
\hline 20 a 30 & 08 & 4,9 & - & - & 08 & 4,4 \\
\hline 31 a 40 & 16 & 9,7 & 03 & 17,6 & 19 & 10,5 \\
\hline 41 a 50 & 22 & 13,4 & 03 & 17,6 & 25 & 13,8 \\
\hline 51 a 60 & 38 & 23,2 & 03 & 17,6 & 41 & 22,6 \\
\hline 61 a 70 & 41 & 25 & 07 & 41,1 & 48 & 26,5 \\
\hline 71 a 80 & 33 & 20,1 & 01 & 5,9 & 34 & 18,8 \\
\hline $810 u+$ & 06 & 3,6 & - & - & 06 & 3,3 \\
\hline Total & 164 & 100 & 17 & 100 & 181 & 100 \\
\hline
\end{tabular}

A mediana da variável idade para todo o grupo foi de 60 anos, com amplitude semi-quartílica (ASQ) de 21 anos. Quanto à mediana da variável idade para o grupo sem infecção, esta foi de 60 anos e para o grupo com infecção, de 54 anos da idade enquanto a ASQ em ambos os casos mostrou-se igual a 22 anos.

De acordo com o teste de Mann-Whitney, ao adotarmos $\alpha=0,01$, não observamos diferença estatisticamente significante entre os grupos, com ou sem infecção, frente à variável idade.

A idade é considerada fator de risco para infecção do sítio cirúrgico (ISC), quando se associa a imunocompetência reduzida, porém esta não deve ser 
considerada isoladamente e, sim, dentro de todo o contexto, como fator de risco moderado (RABHAE; RIBEIRO FILHO; FERNANDES, 2000).

Raymond et al. (2001) analisaram o número de comorbidades presentes entre a população com mais de 70 anos e a população com menos de 70 anos, e concluíram que a ISC foi responsável por alta mortalidade no primeiro grupo. Identificaram, também, doenças cerebrovasculares e infecções fúngicas, como preditores independentes de mortalidade entre idosos.

\subsection{Fatores relacionados ao procedimento cirúrgico}

Em relação à tricotomia, observamos que a maioria dos sujeitos investigados neste estudo não foi submetida a este procedimento $(59,1 \%)$, entretanto, não foi possível determinar pela revisão dos prontuários médicos se a tricotomia, quando realizada, havia sido feita com lâmina ou tricotomizador. Segundo registros da CCIH do hospital onde desenvolvemos o estudo, até o ano 2001 a tricotomia era realizada na enfermaria e com lâmina, porém a partir de 2002 esse procedimento passou a ser feito no Centro Cirúrgico, com tricotomizador elétrico, seguindo as recomendações vigentes na literatura.

Interessante notar que, em 15 casos de infecção, não se realizou a tricotomia, que é reconhecidamente fator predisponente para ISC, o que remete a multicausalidade, isto é, quando um fator isolado não é responsável pela infecção e, sim, a combinação de diversos fatores de risco.

Os estudos encontrados na literatura comprovam que a remoção do pêlo com lâmina da região a ser operada, na noite anterior à cirurgia, é fator mais predisponente a aumento do risco de ISC do que o uso de agentes depilatórios ou a 
não remoção do pêlo. Os pêlos possuem uma microbiota, que não deve ser considerada como fonte importante de patógenos, dada a possibilidade de uma adequada anti-sepsia (APECIH, 2001). Assim, quanto mais curto o tempo entre a tricotomia e a cirurgia, menor será o risco de ISC. Dessa maneira, autores recomendam a realização de tricotomia imediatamente antes da cirurgia, ou no máximo até duas horas antes, desde que estritamente necessária, utilizando-se preferencialmente tricotomizador elétrico (MANGRAM et al., 1999; AORN, 2002).

Outro aspecto interessante reporta-se à antibioticoprofilaxia (ATBP), realizada em todos os sujeitos do grupo do estudo. Em 88,4\% deles, esse procedimento iniciou-se durante a indução anestésica e em 11,6\% em outro momento,como por exemplo, na enfermaria.

A Comissão que controla e regulamenta o uso de antimicrobianos no hospital onde realizamos o estudo, para o tipo de cirurgia investigada (gastrectomias), recomenda o uso de cefazolina $2 \mathrm{~g}$, durante a indução anestésica, e doses de $1 \mathrm{~g}$ a cada 3h de cirurgia, e após, doses de 8/8h, durante 24 horas, utilizando-se a vancomicina como alternativa em casos de pacientes alérgicos (COMISSÃO DE USO E CONTROLE DE ANTIMICROBIANOS - CUCA, 2001/2002).

Frente à descrição presente nos prontuários médicos, pudemos perceber que em 141 pacientes seguiu-se a recomendação do hospital do estudo, quanto ao uso de antibioticoprofilaxia, utilizando-se as doses de reforço, estendendo-as até $24 \mathrm{~h}$ após o procedimento.

Velasco et al. (1997) demonstraram que a ocorrência de ISC foi maior nos pacientes que receberam inadequada ATBP, em comparação ao grupo que utilizou o antimicrobiano da maneira recomendada, apontando como principais causas: o 
momento incorreto de administração em relação à cirurgia, o uso prolongado da droga e a escolha do medicamento inadequado.

Mangram et al. (1999), em relação a antibioticoprofilaxia, fazem quatro recomendações básicas para maximizar os benefícios desta conduta:

- usar ATBP quando comprovadamente houver redução dos índices de ISC;

- usar um antibiótico que seja seguro, barato e com espectro bactericida in vitro que cubra os mais prováveis contaminantes intra-operatórios;

- promover o tempo de infusão da dose inicial do antibiótico de maneira que a concentração bactericida da droga seja estabilizada no sangue e nos tecidos, ao mesmo tempo em que a pele seja incisionada;

- manter os níveis terapêuticos de agentes antimicrobianos no sangue e tecidos, durante a cirurgia e até poucas horas após a incisão ser fechada na sala operatória.

Quanto à anti-sepsia da pele dos pacientes deste estudo, antes da cirurgia, esta foi realizada com PVPI (polivinilpirrolidona) alcoólico em 86,7\% dos casos, sendo que em 11,6\% utilizou-se a combinação de PVPI alcoólico e tópico (aquoso) e nos $3(1,6 \%)$ restantes, com Merthiolate. Na especialidade estudada, a degermação prévia da pele do paciente não é realizada na sala de operação, uma vez que este é orientado a banhar-se com água e sabão, o mais próximo possível da cirurgia.

A preparação da pele com anti-sépticos visa minimizar que microrganismos existentes na microbiota natural da pele sejam levados para dentro da ferida operatória, durante a incisão e manipulação dos tecidos. Vale lembrar, que produtos que contenham em suas formulações mercuriais orgânicos, acetona, quaternário de 
amônio, líquido de Dakin, éter e clorofórmio não são recomendados com a finalidade de anti-sepsia (BRASIL, 1998).

Embora o uso de clorexidina a 4\% elimine mais bactérias gram negativas do que outros produtos (FAOAGALI et al., 1999), e tenha uma maior ação residual, os hospitais utilizam com maior freqüência a solução de polivinilpirrolidona iodo alcoólica que pode ser inativada pelo sangue, ou proteínas séricas, porém, exerce um efeito bacteriostático imediato, quando aplicada na pele (MANGRAM et al., 1999).

Shindo et al. (2002), ao analisarem 45 pacientes submetidos a cirurgias do trato digestivo nos quais se realizou a anti-sepsia com PVPI a 10\% e a utilização adequada da antibioticoprofilaxia. Verificaram a efetividade do uso do PVPI 10\% na redução bacteriana, principalmente em cirurgias potencialmente contaminadas, levando-os a concluir que a solução é efetiva na prevenção de ISC.

Conforme podemos observar na Tabela 2, a maioria dos pacientes $(59,1 \%)$ esteve hospitalizado por até 5 dias antes da realização do procedimento cirúrgico e 25,4\%, de 6 a 10 dias; em 11 dos casos que apresentaram infecção, o período de internação pré-operatório foi de 1 a 5 dias. 
Tabela 2- Distribuição dos pacientes submetidos a gastrectomias em um hospital público, segundo o período de internação pré-operatório (dias) e a presença ou não de infecção do sítio cirúrgico. Ribeirão Preto, 2003

\begin{tabular}{|c|c|c|c|c|c|c|}
\hline \multirow{2}{*}{$\begin{array}{l}\text { Período de } \\
\text { internação pré- } \\
\text { operatório (dias) }\end{array}$} & \multicolumn{2}{|c|}{ Sem infecção } & \multicolumn{2}{|c|}{ Com infecção } & \multicolumn{2}{|c|}{ Total } \\
\hline & $\mathbf{N}$ & $\%$ & $\mathbf{N}$ & $\%$ & $\mathbf{N}$ & $\%$ \\
\hline 1 a 5 & 96 & 58,5 & 11 & 64,7 & 107 & 59,1 \\
\hline 6 a 10 & 44 & 26,8 & 02 & 11,8 & 46 & 25,4 \\
\hline 11 a 15 & 14 & 8,5 & 02 & 11,8 & 16 & 8,8 \\
\hline 16 a 20 & 10 & 6,1 & - & - & 10 & 5,5 \\
\hline 21 a 25 & - & - & - & - & - & - \\
\hline 26 a 30 & - & - & 01 & 5,9 & 01 & 0,5 \\
\hline 31 ou + & - & - & 01 & 5,9 & 01 & 0,5 \\
\hline Total & 164 & 100 & 17 & 100 & 181 & 100 \\
\hline
\end{tabular}

A mediana da variável período de internação pré-operatório, para o grupo como um todo, foi de 4 dias e ASQ, de 6 dias; já a mediana para o grupo sem infecção foi de 4 dias, com ASQ de 6 dias, enquanto para o grupo com infecção a mediana foi de 2 dias e ASQ, de 8 dias. Não observamos diferença estatisticamente significante entre os dois grupos, no que se refere a este período.

Ercole e Chianca (2002) compararam a probabilidade de um sujeito adquirir ISC com o tempo de hospitalização, relatando que pacientes que estiveram de 22 a 47 dias internados, antes do procedimento, tiveram um risco de 11,4 vezes maior de 
contrair infecção do que aqueles cujo tempo de internação pré-operatório foi de até 5 dias. Após a cirurgia, o paciente cuja hospitalização durou mais de 30 dias, apresentou 21,8 vezes mais risco de risco de contrair infecção, em comparação ao paciente que permaneceu internado por tempo inferior a 7 dias. Isto indica que quanto maior o tempo de internação, maior a probabilidade de o paciente contaminar-se com a microbiota hospitalar.

Neste estudo, o período de internação pós-operatório em $45,9 \%$ dos casos foi de 1 a 5 dias, seguido por 41,4\%, de 6 a 10 dias; no grupo como um todo, a mediana para esta variável foi de 6 dias e ASQ de 4 dias. Ressaltamos que, na maioria dos casos (9) em que ocorreu infecção, este período estendeu-se de 6 a 10 dias (Tabela 3). 
Tabela 3- Distribuição dos pacientes submetidos a gastrectomias em um hospital público, segundo o período de internação pós-operatório (dias) e a presença ou não de infecção do sítio cirúrgico. Ribeirão Preto, 2003

\begin{tabular}{|c|c|c|c|c|c|c|}
\hline \multirow{2}{*}{$\begin{array}{l}\text { Período de } \\
\text { internação pós- } \\
\text { operatório (dias) }\end{array}$} & \multicolumn{2}{|c|}{ Sem infecção } & \multicolumn{2}{|c|}{ Com infecção } & \multicolumn{2}{|c|}{ Total } \\
\hline & $\mathbf{N}$ & $\%$ & $\mathbf{N}$ & $\%$ & $\mathbf{N}$ & $\%$ \\
\hline 1a 5 & 82 & 50 & 01 & 5,9 & 83 & 45,9 \\
\hline 6 a 10 & 66 & 40,2 & 09 & 52,9 & 75 & 41,4 \\
\hline 11a 15 & 11 & 6,7 & 02 & 11,8 & 13 & 7,2 \\
\hline 16 a 20 & 04 & 2,4 & 02 & 11,8 & 06 & 3,3 \\
\hline $21 a 25$ & - & - & 01 & 5,9 & 01 & 0,5 \\
\hline 26 a 30 & 01 & 0,6 & 02 & 11,8 & 03 & 1,7 \\
\hline Total & 164 & 100 & 17 & 100 & 181 & 100 \\
\hline
\end{tabular}

A mediana da variável período de internação pós-operatório para o grupo sem infecção foi de 5 dias; para o grupo com infecção, de 9 dias, sendo a ASQ respectivamente de 3 dias e 9 dias.

Notamos diferença estatisticamente significante entre os dois grupos, com ou sem infecção, frente à variável período de internação pós-operatório, apresentando maior tempo de internação o grupo que desenvolveu ISC.

Merle et al. (2000) apontam que o prolongamento da estada hospitalar por ISC pode representar $90 \%$ do custo total da mesma, observando que, nesse estudo, a ISC em paciente submetido à cirurgia do trato digestivo aumentou sua estada independente do método de estimação utilizado. 
$\mathrm{Na}$ Tabela 4, observamos que o período de internação total para o paciente submetido à gastrectomia, em 49,7\% dos casos, foi de até 10 dias, sendo que em 7 dos casos de infecção, a internação total durou de 11 a 20 dias.

Tabela 4- Distribuição dos pacientes submetidos a gastrectomias em um hospital público, segundo o período de internação total (dias) e a presença ou não de infecção do sítio cirúrgico. Ribeirão Preto, 2003

\begin{tabular}{|c|c|c|c|c|c|c|}
\hline \multirow{2}{*}{$\begin{array}{c}\text { Período de } \\
\text { internação (dias) }\end{array}$} & \multicolumn{2}{|c|}{ Sem infecção } & \multicolumn{2}{|c|}{ Com infecção } & \multicolumn{2}{|c|}{ Total } \\
\hline & $\mathbf{N}$ & $\%$ & $\mathbf{N}$ & $\%$ & $\mathbf{N}$ & $\%$ \\
\hline 1 a 10 & 86 & 52,4 & 04 & 23,5 & 90 & 49,7 \\
\hline $11 \mathrm{a} 20$ & 60 & 36,5 & 07 & 41,1 & 67 & 37,0 \\
\hline $21 a 30$ & 16 & 9,7 & 04 & 23,5 & 20 & 11,0 \\
\hline $31 a 40$ & 02 & 1,2 & 02 & 11,7 & 04 & 2,2 \\
\hline Total & 164 & 100 & 17 & 100 & 181 & 100 \\
\hline
\end{tabular}

A mediana da variável período de internação total para o grupo todo foi igual a 11 dias, com ASQ de 8 dias, no entanto, para o grupo sem infecção, a mediana foi igual a 10 dias, com ASQ de 8 dias, enquanto o grupo com infecção apresentou uma mediana de 18 dias e ASQ de 16 dias.

Notamos diferença estatisticamente significante entre os dois grupos, com ou sem infecção, frente à variável período de internação total, apresentando tempo maior de internação o grupo com infecção.

Asensio e Torres (1999), ao quantificarem os efeitos da ISC e período de estada pós-operatória em pacientes submetidos a cirurgias cardíacas, fizeram uma 
comparação entre pacientes infectados e não infectados, e concluíram que a ISC não está apenas associada ao maior período de estada e aumento dos custos, mas também ao aumento da mortalidade nesse grupo de pacientes.

Dentre as cirurgias realizadas no grupo de estudo, observamos que $45,9 \%$ foram gastrectomias totais, $43,1 \%$ descritas apenas como gastrectomias subtotais, 9,4\% especificadas como antrectomia e 1,7\% como pilorectomia.

Tabela 5- Distribuição dos pacientes submetidos a gastrectomias em um hospital público, segundo a duração da cirurgia (horas) e a presença ou não de infecção do sítio cirúrgico. Ribeirão Preto, 2003

\begin{tabular}{|c|c|c|c|c|c|c|}
\hline \multirow{2}{*}{$\begin{array}{l}\text { Duração da } \\
\text { cirurgia } \\
\text { (horas) }\end{array}$} & \multicolumn{2}{|c|}{ Sem infecção } & \multicolumn{2}{|c|}{ Com infecção } & \multicolumn{2}{|c|}{ Total } \\
\hline & $\mathbf{N}$ & $\%$ & $\mathbf{N}$ & $\%$ & $\mathbf{N}$ & $\%$ \\
\hline até 2 horas & 04 & 2,4 & 02 & 11,8 & 06 & 3,3 \\
\hline 2 a 4 horas & 80 & 48,8 & 01 & 5,9 & 81 & 44,7 \\
\hline 4 a 6 horas & 68 & 41,5 & 08 & 47 & 76 & 42,0 \\
\hline+6 horas & 12 & 7,3 & 06 & 35,3 & 18 & 9,9 \\
\hline Total & 164 & 100 & 17 & 100 & 181 & 100 \\
\hline
\end{tabular}

Em relação à duração do procedimento cirúrgico, 44,7\% deles tiveram duração de 2 a 4 horas, seguidos por 42\% que se estenderam por até 6 horas. Em 8 dos indivíduos que desenvolveram infecção, a cirurgia estendeu-se por até 6 horas.

A mediana da variável duração da cirurgia para o grupo todo foi de 4 horas, com ASQ de 2 horas. A mediana para o grupo sem infecção foi de 4 horas de 
cirurgia, com ASQ de aproximadamente 1 hora, enquanto para o grupo com infecção, a mediana foi de 5 horas, com ASQ de aproximadamente 2 horas.

Notamos diferença estatisticamente significante entre os grupos com ou sem infecção, frente à variável duração da cirurgia, apresentando tempo maior de cirurgia o grupo com infecção.

De acordo com os critérios do SENIC, cirurgias com duração maior de duas horas e operações abdominais são associadas com média à moderada hipotermia, grande perda de fluidos e sangue e grande dor pós-operatória, aspectos que levam à vasoconstrição periférica (HOPF et al., 1997).

Medina et al. (1997) afirmam que a duração da cirurgia, bem como o risco de infecção associado à experiência do cirurgião, foram os fatores mais importantes detectados nos pacientes desse estudo. Relatam, também, que a duração da cirurgia não depende exclusivamente do cirurgião, devendo levar-se em conta, também, a doença do indivíduo. Quanto ao risco de infecção associado ao cirurgião, este não deve ser confundido com o risco de infecção intrínseco ao paciente.

$\mathrm{Na}$ literatura, observamos estudos que abordam a habilidade do cirurgião como fator predisponente à infecção, ao apontarem que, quanto maior a habilidade, menor o tempo de exposição e trauma dos tecidos. Porém, Rothwell e Warlow (1999) recomendam cuidado na interpretação do risco individual do cirurgião, pois deve-se considerar, por exemplo, o número de procedimentos realizados, porque as estatísticas baseadas apenas em números finais não evidenciam que aquele cirurgião opera muito mais do que o outro, ou que está presente em mais cirurgias emergenciais, por exemplo.

Wurtz et al. (2001) pesquisaram se os índices de ISC eram maiores ou não em cirurgiões menos experientes, tendo como resultado do estudo que novos 
cirurgiões têm índices mais altos que os mais experientes, demorando mais tempo na realização dos procedimentos. Retrataram, também, que a experiência influi no número de complicações cirúrgicas pós-operatórias.

De acordo com Vilar Compte et al. (2000), há acréscimo no risco de ISC em cada hora a mais de cirurgia, risco que não é muito bem esclarecido por ser facilmente confundido ou estar acompanhado por outros fatores predisponentes. Salientam, ainda, que as primeiras horas após o procedimento cirúrgico são cruciais porque é o momento em que, comumente, se estabelece a ISC (MELLING et al., 2001).

Pessaux et al. (2003), em um estudo prospectivo multicêntrico com 4.718 pacientes submetidos a cirurgias abdominais não cólon-retais, concluíram que o tempo operatório excedente a 120 minutos foi o mais importante fator de risco para as complicações infecciosas.

Neste estudo, observamos que, em relação às transfusões sanguíneas, dos 181 indivíduos estudados, 92 (50,8\%) receberam-nas, o material transfundido foi papa de hemácias, plasma e a combinação de ambos. Dentre os sujeitos que desenvolveram ISC, 15 receberam transfusão de componentes sangüíneos.

Morris et al. (2003), ao analisarem os fatores predisponentes ao desenvolvimento de ISC em pacientes submetidos a cirurgias ortopédicasoncológicas, apontaram a transfusão sangüínea e a obesidade como fatores de risco independentes, verificaram, também, que a quimioterapia e radioterapia anteriores, bem como o uso de esteróides não se mostraram estatisticamente significantes como preditores de ISC.

Tang et al. (2001), em estudo prospectivo com 2.809 pacientes submetidos a cirurgias eletivas de ressecção cólon-retal, concluíram que em qualquer tipo de 
infecção (superficial, profunda ou de órgão/espaço), a transfusão sangüínea foi o fator mais importante, entre todas as variáveis, para determinar a ISC, constatando, ainda, maior incidência de infecção em pacientes que receberam transfusões alogênicas.

Malone et al. (2002) ressaltam dois aspectos relacionados à transfusão sangüínea, realizá-la visando à melhor oxigenação dos tecidos devido ao aumento da capacidade de carrear oxigênio, ou encará-la pelos efeitos imunológicos já esperados.

Greif et al. (2000) procuraram testar a hipótese que a administração suplementar de oxigênio durante o período perioperatório diminui os índices de ISC, em pacientes submetidos a cirurgias eletivas de ressecção cólon-retal, analisando 500 pacientes. Concluíram que a administração de oxigênio por duas horas reduz a incidência de ISC, além de apresentar risco e custos reduzidos, por isso é sugerida como um método prático para diminuição desta onerosa complicação.

No que se refere à população do nosso estudo, verificamos que todos os pacientes operados foram submetidos à sondagem vesical de demora, sendo que, em $68,5 \%$ dos casos, esta sondagem ficou restrita apenas ao dia do procedimento.

No que diz respeito aos pacientes que desenvolveram ISC, estes foram submetidos à sondagem vesical de demora, e dentre estes, 13 permaneceram sondados por até 5 dias.

A mediana para a variável sondagem vesical de demora para o grupo todo foi de 1 dia de permanência do cateter, com ASQ de 1 dia. Para o grupo sem infecção, a mediana foi de 1 dia, com ASQ também de 1 dia; já para o grupo de pacientes que desenvolveu infecção, a mediana foi de 2 dias, com ASQ de 4 dias. 
Notamos diferença estatisticamente significante entre os dois grupos, com ou sem infecção, frente à variável sondagem vesical de demora, apresentando maior tempo de sondagem vesical de demora o grupo com ISC.

A infecção do trato urinário (ITU) é a infecção hospitalar mais freqüente, segundo estudos do CDC, correspondendo de 38,5 a $40 \%$ de todas as infecções nosocomiais. Um dos fatores relevantes para a ocorrência de ITU é a duração do cateterismo vesical, pois sabemos que de 10 a $20 \%$ dos pacientes desenvolverão bacteriúria após a cateterização, mas o risco aumenta de 3 a 10\% para cada dia de permanência com a sonda vesical (GAGLIARDI; FERNANDES; CAVALCANTE, 2000).

Tabela 6- Distribuição dos pacientes submetidos a gastrectomias em um hospital público, segundo a utilização de dreno (dias) e o diagnóstico de infecção do sítio cirúrgico. Ribeirão Preto, 2003

\begin{tabular}{|c|c|c|c|c|c|c|}
\hline \multirow{2}{*}{$\begin{array}{l}\text { Utilização de } \\
\text { dreno (dias) }\end{array}$} & \multicolumn{2}{|c|}{ Não } & \multicolumn{2}{|c|}{ Sim } & \multicolumn{2}{|c|}{ Total } \\
\hline & $\mathbf{N}$ & $\%$ & $\mathbf{N}$ & $\%$ & $\mathbf{N}$ & $\%$ \\
\hline Sem dreno & 94 & 57,3 & 01 & 5,9 & 95 & 52,5 \\
\hline 1 a 10 & 65 & 39,6 & 12 & 70,6 & 77 & 42,5 \\
\hline 11 a 20 & 05 & 03 & 02 & 11,8 & 07 & 3,9 \\
\hline 21 ou + & - & - & 02 & 11,8 & 02 & 1,1 \\
\hline Total & 164 & 100 & 17 & 100 & 181 & 100 \\
\hline
\end{tabular}


Conforme descrito na Tabela 6, dos 181 pacientes estudados, 95 (52,5\%) não utilizaram dreno após a cirurgia; 77 (42,5\%) ficaram de 1 a 10 dias com dreno no pós-operatório, sendo que em 12 dos casos de infecção o dreno permaneceu por até 10 dias. Diante das informações contidas nos prontuários médicos, não conseguimos distinguir o tipo de drenagem (aberto ou fechado), porém sabemos que o dreno de escolha, neste tipo de cirurgia, é o de drenagem fechada. A mediana para a variável utilização de dreno no grupo que permaneceu com esse dispositivo foi de 6 dias, com ASQ de 3 dias. Para o grupo que utilizou dreno, mas não desenvolveu infecção, a mediana foi de 6 dias, com ASQ de 2 dias, enquanto 0 grupo com infecção teve mediana igual a 7 dias e ASQ de 7,2 dias.

Não notamos diferença estatisticamente significante entre os dois grupos, com ou sem infecção, frente à variável utilização de dreno.

Para Mangram (1999), se a drenagem for necessária devemos usar sistemas de drenagem fechados, devendo o dreno deve ser posicionado em uma incisão separada, distante da incisão operatória, e removido tão logo seja possível. Estas recomendações específicas para utilização do dreno são suportadas por pesquisas com delineamento que caracterizam evidências fortes.

Os drenos predispõem o paciente à infecção, e os indivíduos portadores destes apresentam risco de desenvolvê-la por 15 dias, enquanto que, na sua ausência, o risco é de 9 dias. Porém, se o sistema de drenagem for aberto, os índices de ISC podem chegar até a 15,7\%, e em 10,1\% naqueles que possuem sistema de drenagem fechado. Os cirurgiões mesmo cientes desta situação partilham a opinião prevalente que a coleção de fluidos no local da incisão predispõe o paciente à infecção maior e mais extensa do que a que causaria o dreno (SIMCHEN; ROZIN; WAX, 1990). 
Felippe (2003) realizou um estudo de coorte prospectivo para avaliar a incidência de ISC em cirurgias ablativas ou conservadoras de mama, encontrando nas primeiras horas de utilização do dreno ausência de colonização; na segunda amostra, coletada na sua retirada, aproximadamente 14 dias depois do procedimento, a colonização estava presente em 73,5\%.

Buggy (2000) sugere que a abordagem anestésica pode levar à redução de ISC, portanto, compete ao anestesista manter a estabilidade hemodinâmica do corpo humano por meio do balanceamento entre anestésicos e analgesia, contra a estimulação cirúrgica e a perda de fluidos, corrigindo-se assim, a hipovolemia, visando prevenir a vasoconstrição compensatória que prejudica a perfusão tecidual. Em caso de anemia profunda, esta deve ser corrigida pela administração de componentes sangüíneos (transfusão sanguínea), apesar do seu efeito imunossupressivo. Além destes aspectos, o anestesista deve prevenir a hipotermia, já que ela inibe a função dos neutrófilos, prejudicando a proteção do paciente contra a infecção. Assim, a prevenção da hipotermia pode reduzir a incidência de ISC em dois terços, como também a estada hospitalar em um quinto. A otimização da analgesia pós-operatória pode diminuir a ISC, assim como aumentar a concentração de oxigênio administrada no intra e no pós-operatório, principalmente durante a cirurgia e nas primeiras 2 ou 3 horas do pós-operatório, período crítico para o desenvolvimento de ISC, esta medida parece estar associada a uma diminuição dos índices de infecção.

De acordo com Kluytmans e Voss (2002), uma das descobertas mais interessantes no controle de ISC foi o aquecimento do paciente cirúrgico no intraoperatório. 
McAnally et al. (2001) concluíram que a hipotermia é importante fator de risco para ISC em cirurgias cardiotorácicas de crianças, por acarretar efeito imunossupressivo nos neutrófilos, coincidente com a introdução de bactérias patogênicas por meio do procedimento invasivo.

Melling et al. (2001) desenvolveram um estudo randomizado para investigar os efeitos do aquecimento pré-operatório nos índices de ISC, após cirurgias limpas, cujos resultados evidenciaram que trinta minutos de aquecimento antes da cirurgia reduz os índices de infecção. Assim, os autores sugeriram que talvez o aquecimento pré-operatório seja a solução para o controverso uso de antibioticoprofilaxia em cirurgias limpas, que tem sido associado a riscos alérgicos e de resistência bacteriana.

Pessaux et al. (2003) sugerem que os fatores de risco independentes podem ser divididos em quatro categorias, com o objetivo de reduzir o índice de ISC e suas complicações, dentre elas: fatores de risco não modificáveis, como a idade, o sexo; fatores que podem ser melhorados, como o tempo operatório; fatores que podem ser modificados antes ou depois da cirurgia (sobrepeso, tipo de incisão, drenos) e os fatores protetores contra infecção, como o uso de antibióticos.

$\mathrm{Na}$ presente investigação, por se tratar de um estudo retrospectivo, não pudemos coletar as informações referentes aos cuidados com o controle da contaminação ambiental, na sala de cirurgia, e os cuidados relativos aos profissionais envolvidos no procedimento anestésico-cirúrgico (como por exemplo: lavagem e escovação das mãos, paramentação cirúrgica, quebras da técnica asséptica). Assim, não avaliamos estes cuidados já considerados na literatura como fatores predisponentes à ISC. 
A seguir, apresentaremos alguns aspectos relacionados ao uso de barreiras e de controle do ambiente, importantes medidas de prevenção e controle da ISC no transcorrer do procedimento anestésico-cirúrgico.

Segundo Lacerda (2003d, p.262), a paramentação cirúrgica tem como finalidade original "a formação de uma barreira microbiológica contra penetração de microrganismos no sítio cirúrgico do paciente, oriundos dele mesmo, dos profissionais, materiais, equipamentos e ar ambiente". Compõem essa paramentação: uniforme privativo, propé/sapato privativo, gorro, máscara, luvas cirúrgicas, avental e campos cirúrgicos. Associados a estes componentes, estão os óculos, que podem evitar riscos advindos de doenças transmissíveis por substâncias orgânicas oriundas do paciente, por exemplo, a Aids.

Romney (2001), fazendo uma revisão da literatura a respeito da utilização de máscaras durante os procedimentos cirúrgicos, encontrou referência que a ausência de máscaras não alterava os índices de ISC, indicando, porém, que tais estudos não apresentavam desenhos de pesquisa bem delineados, limitando, assim, a aplicação de seus dados na prática diária. Ressaltou que, apesar de não existirem provas científicas de que a utilização de máscaras reduza os índices de infecção, ela serve como proteção para a equipe contra fluidos corpóreos e sangue.

Emsley (2000), também ao fazer uma revisão da literatura sobre este assunto, concluiu não haver evidências que o uso de máscaras reduz o risco de ISC. Salienta o fato de os profissionais exporem os pacientes a risco de infecção cruzada pelo mau uso destas, pois freqüentemente carregam-nas nos bolsos ou ao redor dos pescoços, além de serem tocadas pelo usuário com freqüência.

A Occupational Safety and Health Association (OSHA) sugere o uso de máscaras e protetores oculares para proteção individual contra respingos de material 
potencialmente contaminado e a Association of perioperative Registered Nurses (AORN) recomenda que o profissional a utilize ao adentrar a sala de cirurgia, visando prevenir a contaminação de materiais e equipamentos estéreis, quando abertos (AORN, 1996).

Barbosa (2003) afirma que estudos indicam a necessidade de se realizarem mais pesquisas sobre a eficácia do seu uso, pois os resultados atuais são ainda contraditórios, pela dificuldade em se controlarem as inúmeras variáveis envolvidas no desenvolvimento da ISC. Ressalta, também, a importância das máscaras faciais como barreira de proteção contra respingos de material potencialmente contaminado proveniente do paciente.

Lipp (2003), em uma revisão sistemática sobre o uso da máscara cirúrgica, menciona a escassez de revisões sobre esse tema e o limitado número de estudos clínicos randomizados controlados, o que limita os resultados obtidos e não deixa claro se o uso pode causar dano ou benefício aos pacientes em cirurgias limpas. Assim, recomenda a realização de estudos com delineamento de pesquisas que retratem evidências fortes que determinem conclusivamente os benefícios das máscaras como proteção ao paciente.

Lafreniére et al. (2001) abordam a carência de estudos controlados que investiguem a relação existente entre a paramentação cirúrgica e o risco de ISC. Para os autores, a utilização da vestimenta procura minimizar a contaminação do paciente e a exposição da equipe a fluidos potencialmente contaminados e, assim, recomendam a utilização da mesma vestimenta por até 8 horas, e sua troca caso haja contaminação. Quanto ao uso de propé, parece não alterar os índices de ISC.

Porém, segundo Lacerda (2003c), o uso do propé é questionável, uma vez que não se estabeleceu ainda uma relação entre a dispersão ou transferência de 
bactérias até o sítio cirúrgico com o uso ou não de barreiras protetoras nos pés. Reafirma que estes, quando em condições inadequadas, como molhados, condição freqüente no centro cirúrgico pelo pisoteamento de sangue e fluidos, podem contribuir na dispersão de microrganismos de uma área para outra. Outro aspecto, ressaltado pelo autor consiste na sua colocação e retirada, pois os profissionais de saúde contaminam as mãos com o contato e muitas vezes não realizam a lavagem das mesmas após a colocação e retirada dos propés.

Lacerda (2000) aponta que, apesar das evidências científicas reduzidas frente à efetividade do uso de gorro na prevenção de infecção, este componente da paramentação cirúrgica previne no mínimo a queda de partículas e/ou cabelos dentro do sítio cirúrgico. Segundo Lacerda (2003c), seu uso correto está atrelado, principalmente, à seleção do modelo e do material de confecção, os quais devem ter a capacidade de formar barreira e de permitir a cobertura completa dos cabelos, além de proporcionar conforto para a equipe cirúrgica.

Quanto ao uso das luvas cirúrgicas, estas têm como objetivo estabelecer uma barreira protetora para o paciente da microbiota presente nas mãos da equipe cirúrgica, bem como protegê-la de sangue potencialmente contaminado $(\mathrm{APECIH}$, 2001). Na literatura, alternativas vêm sendo propostas para reduzir a perda da integridade das luvas, dentre elas, o uso de luvas duplas e a troca periódica no transcorrer do procedimento cirúrgico (no máximo a cada duas horas) (LACERDA, 2003c).

No que diz respeito ao uso de aventais, Garcia (2003) considera não haver até o momento evidências de que os aventais descartáveis, ou com reforços que ofereçam impermeabilidade, reduzem efetivamente as taxas de ISC. Salienta que os estudos encontrados na literatura, muitas vezes não caracterizam os diversos 
materiais utilizados na sua confecção, a diferenciação adequada entre aventais descartáveis e reutilizáveis, bem como apresentam falhas metodológicas. O autor sugere que diante das evidências existentes, cada hospital deve adequar o melhor tipo de avental cirúrgico às suas necessidades específicas.

Referindo-se aos campos cirúrgicos, Lacerda (2003c) relata que aqueles confeccionados em tecido de algodão (reprocessável) ainda são os mais utilizados nas instituições de saúde, embora, existam os campos cirúrgicos de não tecido e os de plástico aderente (descartáveis). O autor, fundamentado na revisão sistemática da literatura, afirma não existir estudos contundentes sobre o melhor tipo de campo cirúrgico.

Em relação à dispersão de partículas dentro da sala operatória, recomendamse medidas que coíbam a circulação e concentração exagerada de pessoas dentro da mesma, mantendo obrigatoriamente portas e janelas fechadas, impedindo, assim, a entrada de partículas do meio exterior, de modo a não causar dispersão de bactérias pelo fluxo de ar (GRINBAUM, 1997). Apesar das recomendações preconizadas na literatura sobre o tráfego de pessoas na sala de operação, os estudos de Marton et al. (1999) e Nobre et al. (2001) apontam que a execução desta medida de controle da contaminação ambiental apresenta índice expressivo de inadequação.

Lacerda (2003a) afirma que o número de bactérias que contaminam a ferida ao final do procedimento cirúrgico apresentar-se-á menor, se o nível de contaminação bacteriana do ambiente for pequeno. Ressalta a eficácia do uso de sistemas de ventilação com troca e filtração do ar e pressão positiva para redução da contaminação bacteriana do ar. Este aspecto também é ressaltado por Paula (2003) que, ao analisar a qualidade do ar dentro das salas cirúrgicas ortopédicas, 
constatou que o número de amostras positivas (crescimento microbiano) da entrada do ar condicionado foi menor que da saída, apontando para a necessidade de se utilizar um sistema de climatização artificial adequado que permita a otimização do seu funcionamento, bem como sua manutenção periódica em prol da qualidade de ar isento de risco biológico.

\subsection{Infecção do sítio cirúrgico}

Utilizamos como critério para classificar a topografia dos casos de ISC descritos nos prontuários médicos, o estudo de Mangram et al. (1999), conforme descrevemos abaixo.

A infecção incisional superficial é aquela que ocorre dentro de 30 dias após o procedimento cirúrgico. Envolve apenas pele e tecido subcutâneo do local da incisão cirúrgica e apresenta pelo menos um dos seguintes itens:

- drenagem purulenta com ou sem confirmação laboratorial da incisão superficial;

- organismos isolados por meio de cultura asséptica, obtida de fluidos ou tecidos superficiais;

- ao menos um destes sinais e sintomas de infecção: dor ou sensibilidade local, edema localizado, vermelhidão ou calor local e abertura deliberada da incisão pelo cirurgião, a menos que a cultura da incisão seja negativa;

- diagnóstico de infecção incisional superficial pelo cirurgião.

A infecção incisional profunda ocorre dentro de 30 dias após a cirurgia e no caso de implante de prótese no local até um ano depois, se a infecção puder ser relacionada à operação; além da infecção acometer tecidos moles profundos (fáscia e camadas musculares) deve apresentar pelo menos um dos itens: 
- drenagem purulenta da incisão profunda, mas não de órgãos e espaços componentes do sítio cirúrgico;

- deiscência espontânea de incisão profunda ou a abertura deliberada pelo cirurgião, quando o paciente apresentar pelo menos um destes sinais e sintomas: febre maior que $38^{\circ} \mathrm{C}$, dor localizada, ou sensibilidade, a menos que a cultura local seja negativa;

- abscesso ou outra evidência de infecção, envolvendo tecidos profundos observados ao exame direto durante reoperação ou por histopatologia ou exame radiológico;

- diagnóstico de infecção incisional profunda pelo cirurgião.

Já a infecção de órgão/espaço específica é aquela que ocorre dentro de 30 dias após a cirurgia e no caso de implante de prótese até um ano depois, se a infecção puder ser relacionada à operação ou envolver qualquer parte da anatomia, aberta ou manipulada durante a cirurgia, mas não necessariamente a incisão cirúrgica. Deve apresentar pelo menos um dos itens:

- drenagem purulenta de dreno localizado em órgãos/espaços;

- organismos isolados através de cultura asséptica, obtidos de fluidos ou tecidos em órgãos/espaços;

- abscesso ou outra evidência de infecção, envolvendo órgão/espaço encontrado pelo exame direto durante reoperação, por histopatologia ou exame radiológico;

- diagnóstico de infecção órgão/espaço pelo cirurgião.

Por meio da revisão dos prontuários médicos, constatamos 17 casos de infecção do sítio cirúrgico, sendo que 4 (23,5\%) destes eram infecção incisional superficial; 9 (52,9\%), infecção incisional profunda e 4 (23,5\%), infecção de 
órgão/espaço. Destes 17 casos, 14 (82,3\%) foram diagnosticados durante a internação e $3(17,6 \%)$, no retorno ambulatorial.

A literatura ressalta a importância da vigilância pós-alta, uma vez que os valores poderiam ser subestimados se não houvesse inclusão das infecções diagnosticadas no ambulatório de egressos (LEMOS; OLIVEIRA; SOUSA, 1999; OLIVEIRA et al., 2002).

De acordo com Garner (1986) a taxa média de ISC esperada para cirurgias potencialmente contaminadas é 3 a 11\%, sendo que a taxa de infecção para feridas consideradas limpas é de 1 a 5\%, o que aponta a contaminação endógena como fator principal no desenvolvimento de infecção. As taxas elevadas de infecção em cirurgias limpas podem indicar quebra da técnica asséptica, servindo como índice de comparação entre hospitais e equipes, guardadas as devidas ressalvas.

Conforme podemos observar na Tabela 7, 41,2\% dos casos de infecção desenvolveram-se no período de 6 a 10 dias após a cirurgia. 
Tabela 7- Distribuição dos pacientes submetidos a gastrectomias em um hospital público, segundo o período entre a cirurgia e o diagnóstico de ISC (dias). Ribeirão Preto, 2003

\begin{tabular}{ccc}
\hline $\begin{array}{c}\text { Período entre a cirurgia } \\
\text { e o diagnóstico de ISC }\end{array}$ & $\mathbf{N}$ & \\
(dias) & & \\
\hline 1 a 5 & 05 & 29,4 \\
6 a 10 & 07 & 41,2 \\
11 a 15 & 02 & 11,8 \\
16 a 30 & 03 & 17,6 \\
\hline Total & 17 & 100 \\
\hline
\end{tabular}

Dentre os componentes do grupo de estudo (181 sujeitos), 15 apresentaram outros focos infecciosos que justificaram a utilização de antibióticos, sendo que em 4 destes casos também ocorreu a ISC. Os focos infecciosos descritos apresentaram os seguintes diagnósticos: em 8 casos, a pneumonia; em 4, sepse; em 2, infecções do trato urinário (ITU) e em 1 caso, o diagnóstico foi a combinação de pneumonia e ITU.

Nos 17 sujeitos onde constatamos ISC, em 8 deles não houve solicitação de cultura do microrganismo, enquanto no restante, foram identificados os seguintes microrganismos: Staphylococcus aureus, Staphylococcus epidermidis, Enterobacter faecis, Enterobacter cloacae, Escherichiae coli, Staphylococcus bluolerico, Streptococcus pneumoniae, Streptococcus agalactaeae, Bacteroides fragilis, 
Pseudomonas aeruginosa. Em 5 destes casos, as culturas apontaram mais de um microrganismo.

Como principais causadores de infecção hospitalar, nos EUA, em primeiro lugar está E. coli, seguido pelo S. aureus e, em terceiro, S. epidermidis. A Escherichia coli tem como hábitat natural o intestino do homem e animais, sendo que a forma patogênica da bactéria pode causar infecções do trato urinário, entérica e sistêmica (bacteremia, pneumonia e meningite) (FERNANDES et al., 2000b).

O gênero Staphylococcus é constituído de diversas espécies, sendo amplamente encontrado na natureza, principalmente na pele, anexos e membranas mucosas de mamíferos e pássaros, raramente disseminando-se para outros tecidos. Apresenta grande resistência ao calor, ressecamento e diversas condições ambientais, sobrevivendo extensos períodos em objetos inanimados (FERNANDES et al., 2000b).

Quanto à transmissão destas bactérias, as narinas dos profissionais de saúde estão predispostas à colonização pelo $S$. aureus e estes, comumente, podem transferi-lo aos pacientes através das mãos transitoriamente colonizadas. Oliveira Santos (1996), estudando alunos de um curso de auxiliar de enfermagem, em diversos momentos de sua formação profissional, concluiu que a cavidade nasal foi a área anatômica mais colonizada, seguida da mão direita e mão esquerda.

Outro aspecto importante a ser ressaltado foi a resistência crescente deste microrganismo aos antimicrobianos utilizados para seu tratamento, com cepas meticilino-resistentes (MRSA), resistência que dificulta seu tratamento. Portanto, devemos evitar a disseminação intra-hospitalar, por meio da lavagem das mãos com anti-sépticos, precauções de contato para pacientes com lesões cutâneas, infectados ou colonizados (FERNANDES et al., 2000b). 
Os Streptococcus podem ser isolados na pele, tratos digestivo, respiratório e genital de diversas espécies animais. O Streptococcus agalactiae, natural do trato digestivo, pode colonizar a vagina, canal cervical e uretra. Quanto ao Streptococcus pneumoniae, este coloniza em geral o trato respiratório, podendo ser transmitido pelo de contato direto ou por meio de equipamentos de ventilação mecânica. Enterobacter é um gênero característico da flora humana, oportunistas, que vem desenvolvendo resistência a diversos antibióticos (FERNANDES et al., 2000b).

A Pseudomonas não é própria do homem. É encontrada na água, no esgoto, solo, vegetais e animais, sendo que em seres humanos acaba colonizando regiões de maior umidade (FERNANDES et al., 2000b).

No que se referem aos Bacteróides, têm como seu hábitat natural as vias respiratórias superiores, intestino e genitália feminina, constituindo-se no grupo de anaeróbios mais importante como causadores de infecção. O B. fragilis é responsável por infecções associadas à contaminação pelo conteúdo do cólon, por estar presente nas fezes (GARCIA, 2000).

Assim, em relação à etiologia da ISC, Rabhae; Ribeiro Filho e Fernandes (2000), fundamentados na literatura, descrevem que qualquer agente infeccioso pode ser responsável por este tipo de infecção que, no geral, é causada por agentes presentes na pele ou nas mucosas do próprio paciente. Nas cirurgias limpas, os cocos gram-positivos são mais isolados enquanto nos procedimentos potencialmente contaminados e contaminados são mais freqüentes as bactérias gram-negativas aeróbicas e anaeróbicas. 
Ao analisarmos os dados relativos aos pacientes submetidos a gastrectomias eletivas entre janeiro de 1998 a dezembro de 2002, no hospital investigado, detectamos principalmente:

- o grupo de estudo foi composto de 181 sujeitos, sendo 65 do sexo feminino e 116 do masculino; 140 eram brancos, 23 mulatos, 15 negros e 3 amarelos;

- o diagnóstico médico predominante foi o oncológico (82,3\% do grupo investigado);

- dos 181 sujeitos investigados, observamos que 164 não desenvolveram infecção do sítio cirúrgico (ISC) e 17 desenvolveram-na;

- as variáveis quantitativas contínuas, idade, período de internação pré-operatório e utilização de dreno, não foram associadas neste estudo a ISC;

- as variáveis quantitativas contínuas, período de internação pós-operatório, período de internação total, duração da cirurgia, sondagem vesical de demora foram associadas neste estudo com ISC;

- as variáveis qualitativas, sexo, raça, diagnóstico, etilismo, tabagismo, presença de doenças crônicas, realização de tricotomia, antibioticoprofilaxia, anti-sepsia, tipo de cirurgia, transfusão sangüínea e focos infecciosos em outras topografias, não foram associadas neste estudo com ISC;

- a porcentagem de infecção do sítio cirúrgico foi de 9,4\% em relação à topografia; sendo que $23,5 \%$ dos casos foram classificados como infecção incisional superficial; 52,9\%, como infecção incisional profunda e 23,5\%, como infecção de órgão/espaço. - nos 17 casos em que se constatou ISC, em 8 deles o profissional não solicitou a cultura do microrganismo e, no restante, foram identificados os seguintes microrganismos: Staphylococcus aureus, Staphylococcus epidermidis, Enterobacter faecis, Enterobacter cloacae, Escherichiae coli, Staphylococcus bluolerico, 
Streptococcus pneumoniae, Streptococcus agalactaeae, Bacteroides fragilis, Pseudomonas aeruginosa. Em 5 casos as culturas apontaram mais de um microrganismo. A maioria dos gêneros evidenciados neste estudo constitui-se em microrganismos próprios da microbiota humana que, em virtude da crescente resistência microbiana ou oportunistas, que se aproveitam do estado imunodeprimido do hospedeiro, tornando-se capazes de causar infecção.

Cabe ressaltar que no presente estudo obtivemos as informações por meio dos registros efetuados nos prontuários médicos, portanto, dependentes da qualidade das informações prestadas pelos profissionais de saúde responsáveis pelo atendimento do paciente cirúrgico.

O estudo foi realizado de maneira retrospectiva, o que nos propiciou conhecer, 5 anos da história da ISC em pacientes submetidos a gastrectomias, embora tivéssemos apenas dois anos para sua conclusão. Porém, apesar de coletarmos dados referentes ao período perioperatório e retorno ambulatorial, alguns dados principalmente do período intra-operatório, não foram avaliados, acarretando limitações a presente investigação.

Os resultados mais seguros para interpretar relações causais advêm de estudos com delineamento de pesquisa experimental, como o ensaio clínico randomizado controlado, porque nas outras modalidades de investigação não existe o mesmo grau de certeza nas conclusões. É possível que haja diferenças nas características dos grupos, entre os quais estabelecemos comparações, em virtude da presença de "confundidores" de natureza demográfica, socioeconômica, ambiental, comportamental ou de outra natureza. Estas diferenças podem explicar parte ou a totalidade dos resultados encontrados, o que complica a interpretação (PEREIRA, 2002). 
Apesar das limitações deste estudo, acreditamos que os profissionais de saúde e os que atuam em $\mathrm{CCIH}$, ao terem acesso à análise deste trabalho, poderão verificar as diferenças entre os fatores de riscos presentes nas diversas especialidades médicas e, a partir daí, adotarem medidas de prevenção e controle dirigidas, para a obtenção de melhores resultados, além de questionarem atitudes vigentes.

Particularmente em relação ao paciente cirúrgico, urge elencar todos os atributos que se constituem fatores de risco para infecção, assistindo-o no período perioperatório com intervenções eficazes pautadas no conhecimento científico, que minimizem ou previnam as complicações inerentes ao procedimento anestésicocirúrgico. Seguindo até a vigilância pós-alta, o que permitirá ao profissional conhecer a descrição real dos índices de ISC e demais complicações.

Entendemos a importância de os hospitais implementarem programas educativos que alcancem todos profissionais que atuam nesse contexto, buscando não somente a conscientização, mas também o engajamento, o reconhecimento e a aplicação ou transposição do conhecimento científico para a prática profissional, como peça fundamental no combate à infecção. Também entendemos que é imprescindível a implantação de estratégias que visem garantir a qualidade das informações registradas nos prontuários médicos, tentando transformá-los em retratos precisos da realidade vivenciada, bem como a instituição de impressos próprios para esse fim, que contenham dados necessários para o alcance de estimativas fidedignas sobre $\mathrm{IH}$.

Além disso, para a prevenção e o controle da infecção do sítio cirúrgico e a abordagem dos fatores de risco, recomendamos a consolidação de um programa educativo que envolva toda a equipe multiprofissional, na tentativa de corrigir erros 
relacionados à manutenção dos níveis de glicose, ao controle do tabagismo e etilismo e à correção do estado nutricional, bem como, a enfermagem atuando na manutenção de um ambiente biologicamente seguro, executando procedimentos de limpeza, desinfecção e esterilização dos artigos odonto-médico-hospitalares, o que, culminará no controle da contaminação ambiental da unidade de Centro Cirúrgico. 
ASENSIO, A.; TORRES, J. Quantifying excess length of postoperative stay attributable to infections: a comparison of methods. J Clin Epidemiol, v.52, n.12, p.1249-56, dec.1999. ${ }^{1}$

ASSOCIAÇÃO PAULISTA DE ESTUDOS E CONTROLE DE INFECÇÃO HOSPITALAR (APECIH). Prevenção da infecção de sítio cirúrgico. São Paulo, 1995. 43 p.

ASSOCIAÇÃO PAULISTA DE ESTUDOS E CONTROLE DE INFECÇÃO HOSPITALAR. Prevenção da infecção de sítio cirúrgico. São Paulo (SP); 2001. 76 p.

ASSOCIATION OF OPERATION ROOM NURSES. Recommended practices for maintaining a sterile field. AORN J, v.64, n.5, p.817-821, nov. 1996.

ASSOCIATION OF PERIOPERATIVE REGISTERED NURSES. Recommended practices for skin preparation of patients. AORN J, v.75, n.1, p.184-87, jan. 2002.

BARBOSA, M.H. Paramentação cirúrgica: máscaras faciais. In: LACERDA, R.A. (org). Controle de Infecção em Centro Cirúrgico: fatos, mitos e controvérsias. São Paulo: Atheneu, 2003. Cap.20, p.315-324.

BRASIL. Leis etc. Ministério da Saúde. Portaria nº 2616 de 12 de maio de 1998. Diário Oficial da União, Brasília, 13 maio 1998. Seção 1, p. 133-135.

BRASIL. Resolução n 196 de 10 de outubro de 1996. Dispõe sobre as diretrizes e normas regulamentadoras de pesquisas envolvendo seres humanos. Brasília, Conselho Nacional de Saúde, 10 de out. 1996. Disponível em <http://www.conselho.saude.gov.br/docs/resoluçoes/resol96.doc>. Acesso em: 22/03/2004.

\footnotetext{
${ }^{1}$ De acordo com:

ASSOCIAÇÃO BRASILEIRA DE NORMAS TÉCNICAS. NBR 6023: informação e documentação: referências: elaboração. Rio de Janeiro, 2002.
} 
BUGGY, D. Can anaesthetic management influence surgical-wound healing? Lancet, v.356, n.9227, p.355-57, jul. 2000.

CABTREE, T.D. et al. Gender-dependent differences in outcome after the treatment of infection in hospitalized patients. JAMA, v.282, n.22, p.2143-48, dec. 1999.

CANTURK, N.Z. et al. Risk of nosocomial infections and effects of total cholesterol, HDL cholesterol in surgical patients. Clin Nutr, v.21, n.5, p. 431-36, oct. 2002.

COMISSÃO DE USO E CONTROLE DE ANTIMICROBIANOS (CUCA). Manual de Antimicrobianos. Hospital das Clínicas de Ribeirão Preto, 2001/2002.

DELGADO-RODRÍGUEZ, M. et al. A prospective study of tobacco smoking as a predictor of complications in general surgery. Infect Control Hosp Epidemiol, v.24, n.1, p.37-43, jan. $2003 a$.

DELGADO-RODRÍGUEZ, M. et al. Alcohol consumption and the risk of nosocomial infection in general surgery. Br J Surg, v. 90, n. 10, p. 1287-1293, oct. $2003 \mathrm{~b}$.

DELGADO-RODRÍGUEZ, M. et al. Cholesterol and serum albumin levels as predictors of cross infection, death, and length of hospital stay. Arch Surg, v.137, n.7, p.805-812, jul. 2002a.

DINDO, D. et al. Obesity in general elective surgery. Lancet, v.361, n. 9374, p.2032-35, jun. 2003.

EMSLEY, L. Why wear surgical face masks? Nurs times, v.96, n.27, p.38-9, jul. 2000. 
ERCOLE, F.F.; CHIANCA, T.C.M. Infecção do sítio cirúrgico em pacientes submetidos a artroplastias de quadril. Rev Latino-Am Enfermagem, v.10, n.2, p.157-65, mar/abr. 2002.

ESTRADA, C.A. et al. Outcomes and perioperative hyperglycemia in patients with or without diabetes mellitus undergoing coronary artery bypass grafting. Ann Thorac Surg, v.75, n.5, p.1392-1399, may. 2003.

FAOAGALI, J.L.; GEORGE, N.; FONG, J.; DAVY, J.; DOWSER, M. Comparison of the antibacterial efficacy of $4 \%$ clhorhexidinne gluconate and $1 \%$ triclosan handwash products in a cute clinical ward. AJIC., v.27, n.4, p. 320-326, aug1999.

FELDING, C.; JENSEN, L.M.; TONNESEN, H. Influence of alcohol intake on postoperative morbidity after hysterectomy. Am J Obstet Gynecol, v.166, n.2, p.667-70, feb. 1992.

FELIPPE, W.A.B. Enfermeiras avaliando o perfil da infecção do sítio cirúrgico em unidade de mastologia oncológica. R Enferm UERJ, v.11,n.1, p. 11-7, jan-abr 2003.

FERNANDES, A.T. O desafio da infecção hospitalar: a tecnologia invade um sistema em desequilíbrio. In: FERNANDES, A.T.; FERNANDES, M.O.V.; RIBEIRO-FILHO, N. Infecção hospitalar e suas interfaces na área da saúde. São Paulo: Atheneu, 2000a. Cap. 8, p.129-159.

FERNANDES, A.T et al. Bactérias Aeróbias. In: In: FERNANDES, A.T. FERNANDES, M.O.V.; RIBEIRO-FILHO, N. Infecção hospitalar e suas interfaces na área da saúde. São Paulo: Atheneu, 2000b. Cap. 14, p. 336-403.

FERNANDES, A.T.; RIBEIRO FILHO, N. Infecção hospitalar: desequilíbrio ecológico na interação do homem com a sua microbiota. In: FERNANDES, A.T.; FERNANDES, M.O.V.; RIBEIRO-FILHO, N. Infecção hospitalar e suas interfaces na área da saúde. São Paulo: Atheneu, 2000c. Cap. 9, p.163-213. 
FIELDS, C.L. Outcomes of a postdischarge surveillance system for SSI at a Midwestern regional referral center hospital. AJIC, v.27, n.2, p.158-164, apr-1999.

FLETCHER, R.H.; FLETCHER, S.W.; WAGNER, E.H. Risco. In: FLETCHER, R.H.; FLETCHER, S.W.; WAGNER, E.H. Epidemiologia clínica: elementos essenciais. Artes Médicas,1996. Cap. 5, p. 103-119.

FURNARY, A.P. et al. Continuous intravenous insulin infusion reduces the incidence of deep sternal wound infection in diabetic patients after cardiac surgical procedures. Ann Thorac Surg, v.67, n.2, p.352-62, feb. 1999.

GAGLIARDI, E.M.D.B.; FERNANDES, A.T.; CAVALCANTE, N.J.F. Infecção do Trato Urinário. In: FERNANDES, A.T.; FERNANDES, M.O.V.; RIBEIRO-FILHO, N. Infecção hospitalar e suas interfaces na área da saúde. São Paulo: Atheneu, 2000. Cap. 18, p. 459-478.

GAMA-RODRIGUES, J.; FORONES, N.M. Câncer gástrico. In: PRADO, F.C.P.; RAMOS, J.A.; VALLE, J.R. (org). Atualização terapêutica. São Paulo: Artes Médicas Ltda., 1999. Seção 4, p.271-278.

GARCIA, C. Bactérias anaeróbias. In: FERNANDES, A.T.; FERNANDES, M.O.V.; RIBEIRO-FILHO, N. Infecção hospitalar e suas interfaces na área da saúde. São Paulo: Atheneu, 2000. Cap. 15, p. 404-417.

GARCIA, C.P. Paramentação cirúrgica: aventais. In: LACERDA, R.A. (org). Controle de Infecção em Centro Cirúrgico: fatos, mitos e controvérsias. São Paulo: Atheneu, 2003. Cap.17, p.277-288.

GARNER, J.S. CDC guidelines for the prevention and control of nosocomial infections: guideline for surgical wound infections, 1985. Am J Infect Control, v.14, p.71-80, 1986. 
GIL, A.C. Como classificar as pesquisas. In: GIL, A.C. Como elaborar projetos de pesquisa. São Paulo: Atlas, 2002. Cap.4, p. 41-58.

GREIF, R. et al. Supplemental perioperative oxygen to reduce the incidence of surgical wound infection. N. Engl. J. Med., v.342, n.3, p.161-7, jan.2000.

GRINBAUM, R.S. Infecção do sítio cirúrgico e antibioticoprofilaxia em cirurgia. In: RODRIGUES, E.A.C. (org.). Infecções hospitalares, prevenção e controle. São Paulo: Sarvier, 1997. Cap. 2, p.149-167.

GRUPO DE AVALIAÇÃO DE DESEMPENHO. Relatório de avaliação de desempenho. Hospital das Clínicas de Ribeirão Preto, 2003.

HEINZELMANN, M.; SCOTT, M.; LAM, T. Factors predisposing to bacterial invasion and infection. Am J Surg, v.183, n.2, p.179-190, feb. 2002.

HOLT, P.G. Immune and inflammatory function in cigarette smokers. Thorax, v.42, n.4, p.241-9, apr. 1987.

HOPF, H.W. et al. Wound tissue oxygen tension predicts the risk of wound infection in surgical patients. Arch Surg, v.132, n.9, p.997-1005, sep. 1997.

JONES, J.K.; TRIPLETT, R.G. The relationship of a cigarette smoking to impaired intraoral wound healing. J Oral Maxillofac Surg, v.50, n.3, p. 237-239, mar.1992.

$\mathrm{KIM}$, J. et al. Obesity and the risk of early and late mortality after coronary artery bypass graft surgery. Am Heart J, v.146, n.3, p.555-560, sep. 2003.

LACERDA, R.A. Centro Cirúrgico. In: FERNANDES, A.T.; FERNANDES, M.O.V.; RIBEIRO-FILHO, N. Infecção Hospitalar e suas interfaces na área da saúde. São Paulo: Atheneu, 2000. Cap. 38, p. 789-818.

LACERDA, R.A. Ambiente da sala de operações: fontes de contaminação e relação com infecção em centro cirúrgico. In: LACERDA, R.A. (org). Controle de 
Infecção em Centro Cirúrgico: fatos, mitos e controvérsias. São Paulo: Atheneu, 2003a. Cap.21, p.325-360.

LACERDA, R.A. Infecção Hospitalar e sua relação com a evolução das práticas de assistência à saúde. In: LACERDA, R.A. (org). Controle de Infecção em Centro Cirúrgico: fatos, mitos e controvérsias. São Paulo: Atheneu, 2003b. Cap.1, p.9-23.

LACERDA, R.A. Paramentação cirúrgica: campos, gorros e propés. In: LACERDA, R.A. (org). Controle de Infecção em Centro Cirúrgico: fatos, mitos e controvérsias. São Paulo: Atheneu, 2003c. Cap.18, p.289-298.

LACERDA, R.A. Paramentação cirúrgica: importância no controle de infecção em Centro Cirúrgico. In: LACERDA, R.A. (org). Controle de Infecção em Centro Cirúrgico: fatos, mitos e controvérsias. São Paulo: Atheneu, 2003d. Cap. 16, p.261-275.

LACERDA, R.A.; EGRY, E.Y. As infecções hospitalares e sua relação com o desenvolvimento da assistência hospitalar: reflexões para análise de suas práticas atuais de controle. Rev. Latino-am. Enfermagem, v.5, n.4, p.13-23, out. 1997.

LACERDA, R.A. Produção científica nacional sobre infecção hospitalar e a contribuição da enfermagem: ontem, hoje e perspectivas. Rev Latino-am Enfermagem, v.10,n.1, p.55-63, jan-fev. 2002.

LAFRENIÈRE, R. et al. Infection control in the operating room: current practices or sacred cows? J Am Coll Surg, v. 193, n.4, p.407-16, oct. 2001.

LEMOS, F.N.; OLIVEIRA, A.V.; SOUSA, M.G. Infecção de sítio cirúrgico: estudo prospectivo de 2149 pacientes operados. Rev. Col. Bras. Cirurgiões, v.26, n.2, p. 109-13, mar-abr, 1999. 
LILIENFIELD, D.E.; VLAHOV, D.; TENNEY, J.H.; McLAUGHLIN, J.S. Obesity and diabetes as risk factors for postoperative wound infections after cardiac surgery. Am J Infect Control, v.16, n.3-6, 1988.

LIPP, A.L. A guide to developing a systematic review. AORN J, v.78, n.1, p.90107, jul. 2003.

LOBIONDO-WOOD, G.; HABER, J. Desenhos não-experimentais. In: LOBIONDO-WOOD, G.; HABER, J. Pesquisa em Enfermagem: métodos, avaliação crítica e utilização. 4 ed. Rio de Janeiro: Guanabara-Koogan, 2001. Cap. 8, p.110-121.

KLUYTMANS, J.; VOSS, A. Prevention of postsurgical infections: some like it hot. Curr Opin Infect Dis, v.15, n.4, p.427-432, aug. 2002.

MALONE, D.L. et al. Surgical site infections: reanalysis of risk factors. J Surg Res, v.103, n.1, p.89-95, mar. 2002.

MANGRAM, A.J. et al. Guideline for prevention of Surgical Site Infection, 1999. AJIC, v.27, n.2, p.97-132, apr.1999.

MARTON, E.S.; SANTOS, M.C.L.; LACERDA; R.A. Controle ambiental em S.O. SOBECC, v.4, n.4, p.16-22, out/dez., 1999.

MATSA, M. et al. Bilateral skeletonized internal thoracic artery grafts in patients with diabetes mellitus. J. Thorac. Cardiovasc. Surg, v.121, n.4, p. 668-74, apr2001.

McANALLY, H.B. et al. Hypothermia as a risk factor for pediatric cardiothoracic surgical site infection. The Pediatric Infect Dis J., v.20, n.4, p.459-62, apr-2001.

MEDINA, M. et al. Risk factors of surgical wound infection in patients undergoing herniorrhaphy. Eur J Surg, v.163, n.3, p.191-98, mar-1997. 
MEININGER, J.C. Epidemiologic designs. In: BRINK, P.J.; WOOD, M.J. Advanced design in nursing research. California: SAGE, 1998. Cap. 9, p. 210235.

MELLING, A.C. et al. Effects of preoperative warming on the incidence of wound infection after clean surgery: a randomised controlled trial. The Lancet, v.358, n.9285, p.876-80, sep-2001.

MERLE, V. et al. Assessment of prolonged hospital stay attributable to surgical site infections using appropriateness evaluation protocol. AJIC, v.28, n.2, p.109115, apr. 2000.

MORRIS, C.D. et al. Prospective identification of risk factors for wound infection after lower extremity oncologic surgery. Ann Surg Oncol, v.10, n.7, p.778-782, aug. 2003.

MYLES, P. S. et al. Risk of respiratory complications and wound infection in patients undergoing ambulatory surgery: smokers versus nonsmokers. Anesthesiology, v.97, n.4, p. 842-7, oct. 2002.

NEVES, J. Infecção hospitalar no contexto da formação dos profissionais da saúde. Arq Bras Med, v.68, n.5, p.313-316, set/out. 1994.

NEVES, J. Marcos históricos das infecções hospitalares e seu controle. Arq Bras Med, v.67, n.3, p. 167-172, maio/junho 1993.

NOBRE, I.F. et al. Avaliação de indicadores do controle da contaminação ambiental da sala de operação: um estudo piloto. Medicina, v.34, n.2, p.183-193, abr-jun 2001.

OLIVEIRA, A.C. et al. Estudo comparativo do diagnóstico da infecção do sítio cirúrgico durante e após a internação. Rev Saúde Pública, v.36, n.6, p.717-22, dez. 2002. 
OLIVEIRA SANTOS, B.M. O portador são de Staphylococcus aureus: um estudo longitudinal em alunos de um curso de auxiliar de enfermagem. 1996. 212 p. Tese (Livre Docência) - Escola de Enfermagem de Ribeirão Preto, Universidade de São Paulo, Ribeirão Preto.

OLSEN, M.A. et al. The risk factors for deep and superficial chest surgical-site infections after coronary artery bypass graft surgery are different. J. Thorac. Cardiovasc. Surg, v. 124, n.1, p.136-145, jul. 2002.

PAULA, J.F.L. Aeromicrobiota do ambiente cirúrgico: princípios e peculiaridades da climatização artificial. 2003. 111 p. Dissertação (Mestrado) - Escola de Enfermagem de Ribeirão Preto, Universidade de São Paulo, Ribeirão Preto.

PEREIRA, M.G. Epidemiologia teoria e prática. Rio de Janeiro: Guanabara Koogan, 2002. Cap. 12, p. 269-287.

PESSAUX, P. et al. Risk factors for postoperative infectious complications in noncolorectal abdominal surgery: a multivariate analysis based on a prospective multicenter study of 4718 patients. Arch Surg, v.138, n.3, p.314-24, mar. 2003.

POULSEN, K.B. et al. Estimated costs of postoperative wound infections: a case control study of marginal hospital and social security costs. Epidemiol Infect, v.113, n.2, p.208-295, oct. 1994.

POVEDA, V.B.; GALVÃO, C.M.; HAYASHIDA, M. Análise dos fatores de risco relacionados à incidência de infecção do sítio cirúrgico em gastrocirurgias. Rev Esc Enferm USP, v.37, n.1, p.81-9, mar. 2003.

RABHAE, G.N.; RIBEIRO FILHO, N.; FERNANDES, A.T. Infecção do sítio cirúrgico. In: FERNANDES, A.T. et al. Infecção hospitalar e suas interfaces na área da saúde. São Paulo: Atheneu, 2000. Cap. 19, p. 479-505. 
RANTALA, A.; LEHTONEN, O.P.; NIINIKOSKI, J. Alcohol abuse: a risk factor for surgical wound infections? Am J Infect Control, v.25, n.5, p.381-6, oct. 1997.

RAYMOND, D.P. et al. Surgical infection and aging population. Am Surg, v.67, n.9, p.827-33, sep. 2001.

REILLY, J. et al. An economic analysis of surgical wound infection. J Hosp Infect, v.49, n.4, p.245-49, dec. 2001.

ROMNEY, M.G. Surgical face masks in the operating theatre: re-examining the evidence. J Hosp Infect, v.47, n.4, p.251-256, apr. 2001.

ROTHWELL, P.M.; WARLOW, C.P. Interpretation of operative risks of individual surgeons. Lancet, v.353, n.9163, p.1325, apr. 1999.

SHINDO, K. et al. Clinical study on the antiseptic effect of povidone-iodine solution for the surgical field of digestive tract operations. Dermatology, v.204 (suppl 1), p. 47-51, 2002.

SIMCHEN, E.; ROZIN, R.; WAX, Y. The Israeli study of surgical infection of drains and the risk of wound infection in operations for hernia. Surg. Gynecol. Obstet., v.170, n.4, p.331-337, apr.-1990.

SORENSEN, L.T. et al. Smoking as a risk factor for wound healing and infection in breast cancer surgery. Eur J Surg Oncol, v. 28, n.8, p.815-820, dec. 2002.

TANG, R. et al. Risk factors for SSI after elective resection of the colon and rectum: a single-center prospective study of 2809 consecutive patients. Ann Surg, v. 234, n.2, p.181-9, aug. 2001.

TONNESEN, H.; SCHÜTTEN, B.T.; JORGENSEN, B.B. Influence of alcohol on morbiity after colonic surgery. Diseases of the Colon \& Rectum, v.30, n.7, p.549-51, jul. 1987. 
VELASCO, E. et al. Profilaxia antimicrobiana em cirurgias oncológicas. Rev. Hosp. Clín. Fac. Med. S. Paulo, v.52, n.4, p. 209-16, jul-ago. 1997.

VILAR-COMPTE, D. et al. Surgical site infections at the National Cancer Institute in Mexico: a case control study. AJIC, v. 28, n.1, p.14-20, feb-2000.

WURTZ, R. et al. Do new surgeons have higher surgical-site infection rates? Infect Control Hosp Epidemiol, v.22, n.6, p.375-77, jun. 2001.

ZERR, K.J. et al. Glucose control lowers the risk of wound infection in diabetics after open heart operations. Ann Thorac Surg, v.63, n.2, p.356-361, feb. 1997. 
APÊNDICE A - parte 1

INSTRUMENTO DE COLETA DE DADOS

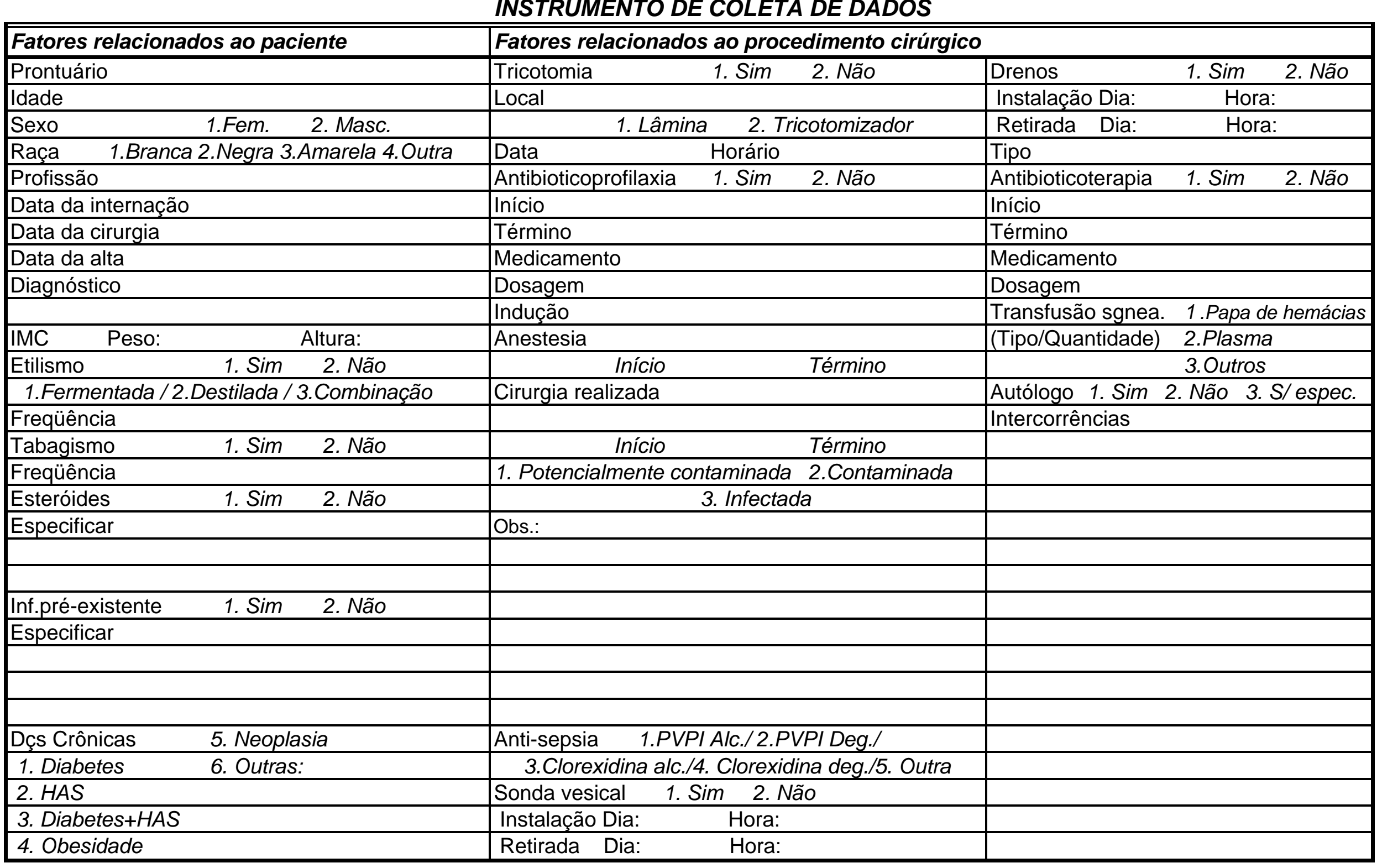


APÊNDICE B - parte 2 INSTRUMENTO DE COLETA DE DADOS

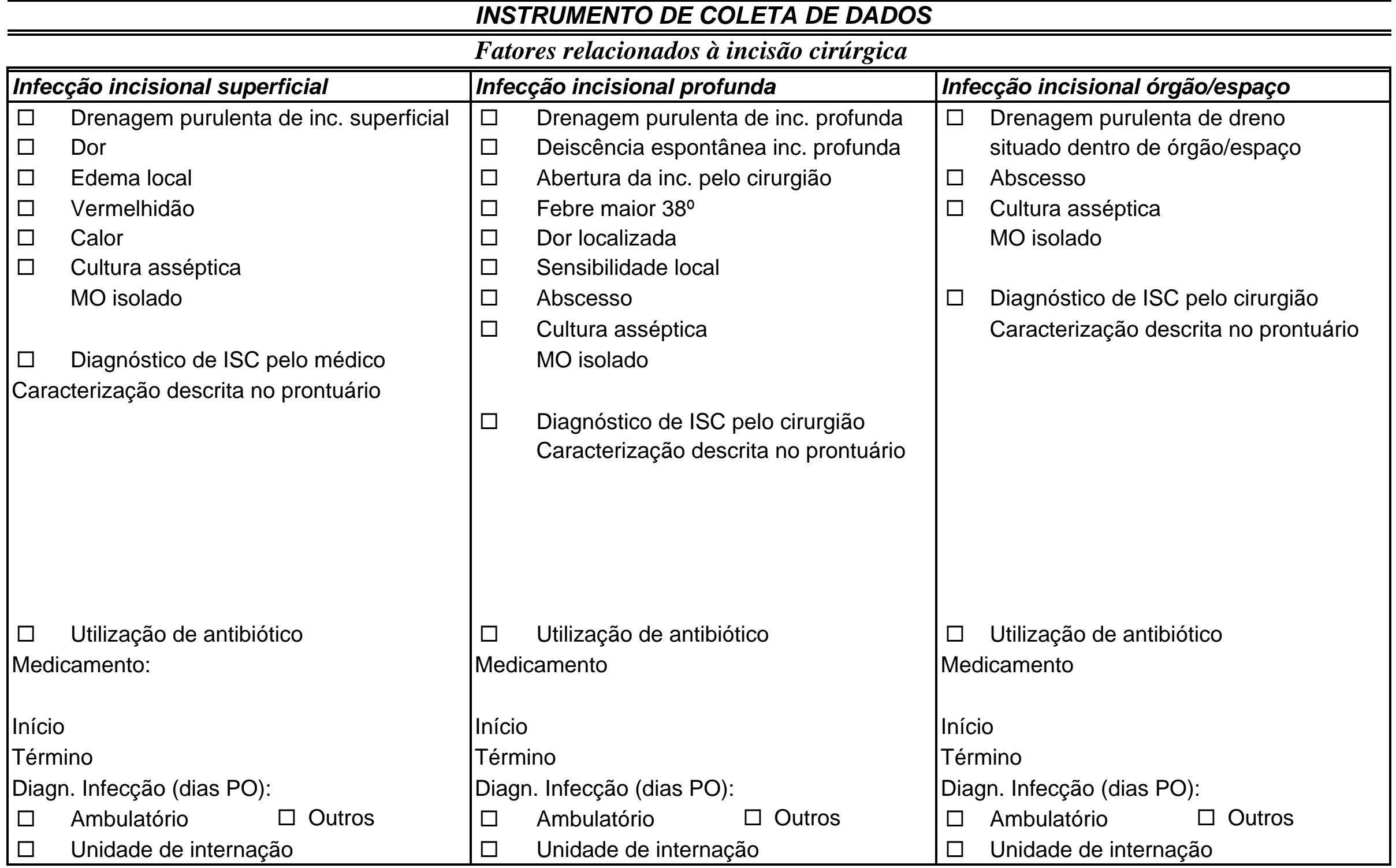

